Article

\title{
A Review of the Tribe Cryptoplini (Coleoptera: Curculioninae), with Revision of the Genus Menechirus Hartmann, 1901 and Description of a New Genus Associated with Macadamia
}

\author{
Debbie Jennings * and Rolf G. Oberprieler \\ CSIRO Australian National Insect Collection, P.O. Box 1700, Canberra, A.C.T. 2601, Australia; \\ rolf.oberprieler@csiro.au \\ * Correspondence: debbie.jennings@csiro.au; Tel.: +612-6246-4234 \\ http:/ / zoobank.org/urn:lsid:zoobank.org:pub:CF5DC45F-61F7-41C3-ACFD-3BDF34CCF20D \\ Received: 6 June 2018; Accepted: 15 July 2018; Published: 23 July 2018
}

\begin{abstract}
This paper presents the results of a study that was largely initiated to describe a genus and species of weevil damaging macadamia fruits in plantations in New South Wales and Queensland, Australia. This taxon is described as Kuschelorhynchus macadamiae gen. et sp. n., the genus named in honour of the late Guillermo (Willy) Kuschel (1918-2017). The related genus Menechirus Hartmann is also revised, resulting in the description of three new species, $M$. howdenae sp. n., M. parryi sp. $\mathrm{n}$. and M. mundus sp. $\mathrm{n}$. The other genera of the small Australian weevil tribe Cryptoplini, Cryptoplus Erichson, Haplonyx Schoenherr, Sigastus Pascoe and Zeopus Pascoe, are diagnosed and their host associations summarised, and a revised diagnosis of the tribe Cryptoplini is presented, together with a key to its six genera. The extraordinary aedeagus of Cryptoplini, featuring a tectal plate as is characteristic of more primitive weevils, is discussed and illustrated.
\end{abstract}

Keywords: Cryptoplini; taxonomy; weevils; tectal aedeagus; Kuschelorhynchus; Macadamia; Syzygium; Australia; New Guinea

\section{Introduction}

The weevil tribe Cryptoplini as currently known is confined to Australia except for one species, Menechirus oculatus Hartmann, which occurs in New Guinea [1]. The taxon was first established as a group Cryptoplides in Lacordaire's tribe Erirhinides, which included as other groups the true Erirhinides, Eugnomides, Hydronomides and Storeides [2]. Originally, the Cryptoplides included besides Cryptoplus Erichson, 1842 seven other genera, all of which have since been removed from this tribe. The single species placed in Cryptoplus by its author, C. perdix Erichson, 1842 [3], remained unknown to authors such as Lacordaire, Pascoe and Blackburn, and Lea only managed to examine its type in 1931, discovering that it is congeneric with Aolles Pascoe, 1870 [4], which had been described later in the tribe Haplonychini Lacordaire, 1865 [5]. Lea consequently transferred Cryptoplus to Haplonychini (as Haplonycides) but failed to realise that the name of this tribe then became a junior synonym of the older name Cryptoplini Lacordaire, 1863. This error was perpetuated in the literature until the end of the 20th century, being rectified only in 1999 [6].

The early work on the taxonomy of the Cryptoplini (as Haplonychinae) was undertaken by Pascoe [5], who added the genera Aolles and Sigastus Pascoe, 1865 as well as Metatyges Pascoe, 1865 and Physarchus Pascoe, 1865 to this previously monotypic tribe. However, the last two of these genera are now classified in a different tribe, Metatygini, with the name Metatyges as a synonym of Omophorus Schoenherr, 1835. Lea also made significant contributions to the knowledge of the Cryptoplini, being the first to develop a basic key to its genera [7], undertake a review of the large genus Haplonyx 
Schoenherr, 1836 [8], describe many new species [7-11] and eventually discover that Cryptoplus is congeneric with Aolles [4]. Since Pascoe and Lea, the Cryptoplini have only received little and sporadic taxonomic attention. Zimmerman [12] added the genera Cranopoeus Marshall, 1931, Cratoscelocis Lea, 1927, Fergusoniella Alonso-Zarazaga \& Lyal, 1999 and Spanochelus Marshall, 1931 to the tribe, but these were subsequently placed in a separate tribe, Cranopoeini [13]. Zimmerman also discovered that Sigastus tropicus Lea, 1928 had previously been described as Menechirus fuscodorsalis Heller, 1922 [12], but neither he nor Lea were familiar with the genus Menechirus Hartmann, 1901 and neither assigned it to Cryptoplini, nor did Schenkling \& Marshall [14] in their catalogue of the tribe nor Alonso-Zarazaga \& Lyal [6], who listed it in the tribe Trigonocolini. Pullen et al. [15] recently started to clarify the blurred concept of Sigastus by transferring S. casuarinae Lea, 1909 to Haplonyx and, having examined the type species of Menechirus, the New Guinean M. oculatus Hartmann, 1901, synonymised Menechirus with Sigastus. Caldara et al. [1] provided a summary of the composition, distribution, characters and biology of the tribe. Currently it includes only four genera, Cryptoplus, Haplonyx, Sigastus and Zeopus Pascoe, 1872, all however in need of further study and delimitation. In this paper, we reinstate Menechirus as a valid genus, clarify its concept and characters and describe three new species in it, and we describe an additional, related new genus and species from Australia.

Cryptoplini are largely associated with the plant family Myrtaceae, some taxa apparently being quite host-specific. Cryptoplus, Haplonyx, Sigastus and Zeopus are predominantly associated with Eucalyptus, the larvae developing in flower and fruit buds but also in galls, often those incited by other insects, such as brachyscelid coccids [16], wasps and fergusoninid flies [17]. The females typically lay a single egg into a bud and then cut off the entire cluster of buds [18], which can result in large-scale budfall in some regions and years. In large woody galls, several larvae may develop together. Some Haplonyx species have also been recorded as developing in the flower buds of Melaleuca and in galls on Leptospermum, whereas H. casuarinae has been reared from fruits and coccid galls of Casuarina (Casuarinaceae). Menechirus develops in the fleshy fruits of Syzygium (often recorded as Eugenia on host labels, also as Acmena and Waterhousea) and perhaps also in those of Rhodomyrtus. In contrast to these associations with Myrtaceae, the new genus and species described here, Kuschelorhynchus macadamiae, lives on Macadamia (Proteaceae), being regarded as an emerging pest of macadamia nuts in north-eastern New South Wales and north-eastern Queensland [19-22]. The naming and description of this taxon, as well as of an undescribed Menechirus species associated with the endangered Magenta Lilly Pilly (Syzygium paniculatum) in New South Wales, is a further aim of this paper.

\section{Materials and Methods}

\subsection{Specimens}

The study is based on 233 specimens of Menechirus and Kuschelorhynchus. In addition, numerous specimens of the other genera were examined for a comparison of characters. The genitalia of 47 relevant specimens were dissected in the usual manner, by extracting the ventrites and terminalia of softened specimens under the microscope, macerating them in a hot solution of $10 \% \mathrm{KOH}$, rinsing them in ethanol and then clearing and storing them in glycerol, initially on cavity slides and later in microvials attached to the pins of the specimens. All specimens are deposited in the Australian National Insect Collection (ANIC), CSIRO, Canberra, except where otherwise indicated, as follows:

CMNC Canadian Museum of Nature, Ottawa, Canada

QDPI Queensland Department of Primary Industries Insect Collection, Brisbane, Australia

QMBA Queensland Museum, Brisbane, Australia

\subsection{Descriptions and Label Data}

Body length was measured from the anterior tip of the pronotum to the apex of the elyta in lateral view, and width was measured across the widest expanse of the structure. The terms of the 
structures are those commonly used in weevils [23], whereby tarsite is preferred over tarsomere for the tarsal segments (following Kuschel, Zimmerman and Oberprieler, akin to sternite, ventrite and similar terms and also consistent with the common term cryptotarsite used for the hidden, fourth segment in Phytophaga), and onychium is used for the terminal, claw-bearing tarsite (also following Kuschel and others). In the spermatheca, the term collum refers to the part in which the duct is inserted, when this is differentiated. In the antennae, the term segment is used purely in a descriptive sense, as part of a larger structure, thus the club comprising four segments when they are discernible as such. Label data are given verbatim, a slash (/) denoting different lines on a label and a double slash $(/ /)$ denoting different labels on the same specimen pin.

\subsection{Illustrations}

Photographs of weevils and their genitalia were taken using a Leica DFC500 camera mounted on a Leica M205C microscope. Photographs taken at different focus levels were combined into single images using the software program Leica Application Suite (LAS) V4.9, and these images were enhanced as necessary using the Photoshop CS6 software. Scanning electron microscope (SEM) images were taken using a Hitachi TM3030Plus Tabletop Microscope and enhanced as necessary using the Photoshop CS6 software.

\section{Systematics}

\subsection{Diagnosis of the Tribe Cryptoplini}

Tribe Cryptoplini Lacordaire, 1863

Cryptoplides Lacordaire, 1863: 486 [2]

Haplonycides Lacordaire, 1865: 16 [24]

Diagnosis (modified after Lea [11] and Caldara et al. [1]). Elytra uniformly convex from base to apex; pronotum and elytra densely squamose; rostrum usually stout and relatively straight (except for Zeopus); maxillary and labial palps 3-segmented; funicles 6- or 7-segmented, with segment 7 sometimes closely appressed or fused to club, resulting in a 4- or 5-segmented club, clubs elongate; procoxae narrowly separate to contiguous (Zeopus); femora dentate with one or more unequal teeth; tibiae with large uncus and smaller premucro inside a tuft of setae; tarsi with onychium narrow or reduced to absent; claws simple and either connate, single or absent; proventriculus undifferentiated, lacking plates and paired brushes; penis with tectal plate fused with pedon at base; gonocoxites without styli, spermathecal gland with sclerotised funnel-shaped base.

Remarks. This small tribe is well characterised by the unusual tectal plate of the penis, the sclerotised, funnel-shaped base of the spermathecal gland and the undifferentiated proventriculus, characters that indicate it to constitute a monophyletic group. The delimitation of its six genera, however, is in need of further study, as their traditional distinguishing characters, the segmentation of the funicles and the condition of the tarsal claws [7], are variable and not easy to segregate into distinct conditions. The six-segmented funicles of Cryptoplus and Zeopus are due to the seventh (last) segment being more or less closely appressed to the club, a condition that may, as in other weevils, have originated several times, and the fine claws vary from being separate but parallel in Menechirus, Sigastus and Kuschelorhynchus to largely fused (separate at the apex) in a few Haplonyx species to a single claw in most Haplonyx and some Cryptoplus species to being entirely absent in most species of Cryptoplus and in Zeopus. To this end, the distinction between Cryptoplus and Haplonyx has been questioned before $[4,9,10]$, and the distinction between Cryptoplus and Zeopus is equally tenuous based on these features. More comprehensive study of all species of these three genera is required to place their distinction on a more secure footing. 


\subsection{Key to the Genera of Cryptoplini}

1. Funicles 6-segmented, last segment appressed to club, this appearing 5-segmented; tarsi with onychium minute, hidden in apical cleft of third tarsite, usually clawless

- $\quad$ Funicles 7-segmented, clubs 4-segmented; tarsi with distinct, exposed onychium bearing one or two claws .....

2. Rostrum short, straight to slightly curved; penis with flat, symmetrical endophallic sclerite; spermathecal gland bulbous Cryptoplus

- $\quad$ Rostrum long and thin, distinctly curved; penis with bent, twisted, double endophallic sclerite; spermathecal gland mushroom-shaped ... Zeopus

3. Onychia with single claw (rarely apically bifid) Haplonyx

- $\quad$ Onychia with two separate claws, divergent or parallel 4

4. Rostrum apically broadened in dorsal view only, narrowed or straight in lateral view; pronotum with two pairs of small, low admedian tubercles; elytra with three to four pairs of small, low tubercles Menechirus

- Rostrum apically broadened in dorsal and lateral view; pronotum with two pairs of large, fasciculate admedian tubercles and one to two pairs of smaller lateral ones; elytra with seven or eight pairs of larger, sometimes fasciculate tubercles

5. Funicle segments 7 closely appressed to club (funicles appearing 6-segmented); body sparsely covered with black hair-scales; elytra with eight pairs of large fasciculate tubercles on interstriae 3 and 5, apically rounded; claws closely associated and parallel Sigastus

- $\quad$ Funicle segments 7 separate from club (funicles distinctly 7-segmented); body densely covered with greenish-grey scales (reddish-brown on pronotal tubercles); elytra with one pair of huge, compressed, squamose tubercles on interstriae 3 and with four smaller tubercles anterolaterally of these, apically truncate; claws separate and slightly divergent ..... Kuschelorhynchus

\subsection{Diagnoses of the Genera of Cryptoplini}

Genus Cryptoplus Erichson, 1842 (Figure 1)

Cryptoplus Erichson, 1842:198 [3] (type species, by monotypy: Cryptoplus perdix Erichson, 1842)

Aolles Pascoe, 1870:450 [5] (type species, by subsequent designation [15]: Aolles rubiginosus Pascoe, 1870); Lea, 1931:50 [4] (synonymy)

Diagnosis. Body small, oval in dorsal view (Figure 1a), uniformly convex in lateral view; rostrum moderately long, straight to slightly curved (Figure 1b); antennae inserted in apical third of rostrum, with funicle 6-segmented and club 5-segmented (Figure 1c); pronotum trapezoidal, punctate; procoxae narrowly to very narrowly separate; elytra punctate, squamose with varying patterns; scutellar shield oval to roundly triangular; tarsi with onychium small, hidden in apical cleft of tarsite 3 , usually clawless (Figure 1d), rarely with a small single claw; penis with apical margin of pedon narrowed, temones long; endophallus spinulose, with weak pair of elongate internal sclerites (Figure 1e) (C. fasciatus (Lea), C. maculipennis (Lea)); gonocoxites elongate, apically narrowed, bursa copulatrix elongate (Figure 1f), spermatheca thickly crescentic, gland oval with sclerotised funnel-shaped base (Figure 1g). 

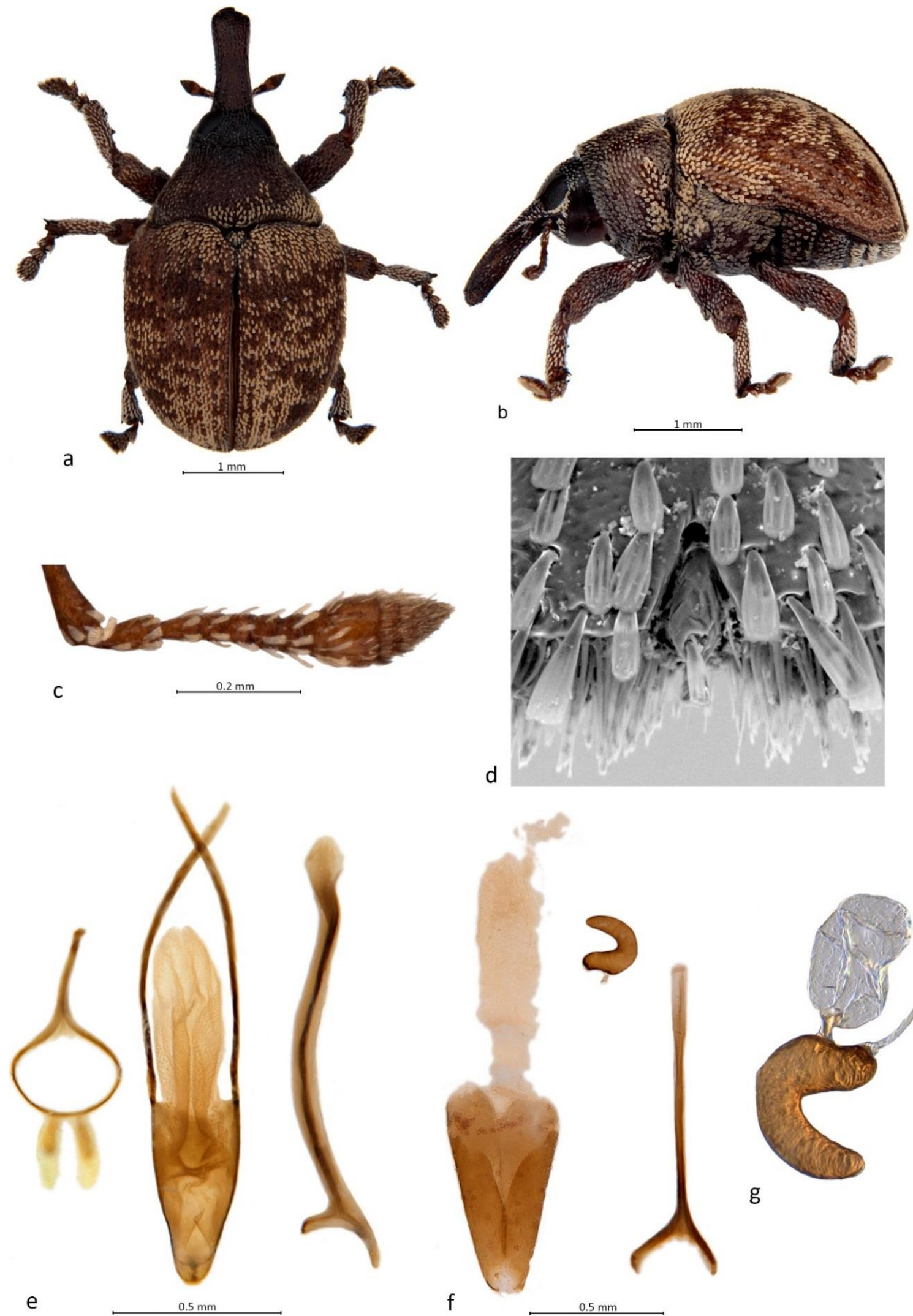

Figure 1. Habitus and diagnostic characters of Cryptoplus Erichson (C. maculipennis (Lea)): (a) habitus of male, dorsal view; (b) habitus of male, left lateral view; (c) right antenna, male, dorsal view; (d) tarsite 3 with onychium, apical view; (e) genitalia, male, dorsal view; (f) genitalia, female, dorsal view; (g) spermatheca with gland. 
Remarks. This genus currently comprises 33 species [15] and is largely associated with Eucalyptus [1,25], the females laying their eggs into flower buds and severing the bud clusters afterwards [26]. Erichson's original description is incorrect in that the funicles are described as being seven-segmented, but Lea (1931) [4], on examination of the type of C. perdix, noted this error and confirmed that they are six-segmented. On this character Cryptoplus and Zeopus can be readily distinguished from Haplonyx, Kuschelorhynchus, Menechirus and Sigastus, all of which have seven-segmented funicles. However, Cryptoplus is difficult to distinguish from Zeopus, the latter sharing its tarsal condition and only differing in having a much longer, curved rostrum and some dissimilar genital structures. Cryptoplus typically has extremely reduced onychia, concealed in a small short cleft at the apex of the third tarsite and bearing no claw but one or two short stiff setae (Figure 1d), although a few species, such as C. ornatipennis (Blackburn), C. tibialis (Lea), C. trifasciatus (Lea) and C. variegatus (Lea), possess longer onychia protruding from the apex of the third tarsites and bearing a single small claw (as well as setae). Lea's (1927) [7] assertion that C. tibialis has two claws is incorrect; all specimens in the ANIC so identified have a distinct single claw.

Genus Haplonyx Schoenherr, 1836 (Figures 2 and 3)

Haplonyx Schoenherr, 1836: 606 [27] (type species, by original designation: Haplonyx spencei Gyllenhal, 1836)

Diagnosis. Body short, oval in dorsal view (Figures 2a and 3a), distinctly convex in lateral view (Figures $2 b$ and $3 b$ ); rostrum robust, moderate in length, straight to slightly curved (Figures $2 b$ and $3 b$ ); antennae with funicle clearly 7-segmented and club 4-segmented (Figures $2 \mathrm{c}$ and $3 \mathrm{c}$ ); procoxae separate; elytra punctate, squamose with varying patterns; scutellar shield oval to roundly triangular; tarsi with onychium narrow but distinct, with a single claw (Figure 2d) or an apically shortly bifid one (H. casuarinae, Figure 3d); penis parallel-sided with rounded apex (Figure 2e) to navicular with pointed apex (Figure 3e); endophallus spinulose, with internal sclerites variable (Figures 2e and 3e); gonocoxites apically narrowed with apical setae (Figure 2f) to truncate and setose (Figure 3f), spermatheca crescentic with elongate, oval gland (Figures $2 \mathrm{~g}$ and $3 \mathrm{~g}$ ).

Remarks. Haplonyx is a large and variable genus, currently comprising approximately 61 species, but numerous synonymies are indicated [15] and many undescribed species are in collections. The genus is in need of thorough revision. Its most distinguishing feature are the single tarsal claws (Figure 2d), but in $H$. casuarinae the claws are apically shortly bifid (indicating fusion of an original pair) (Figure 3d), and in some Haplonyx specimens there is a much reduced but free claw present on the inside of the large one. Most Haplonyx species appear to develop in flower and fruit buds like those of Cryptoplus do, but several develop in woody galls incited by brachyscelid coccids, Hymenoptera or by the weevil larvae themselves $[1,8,16,25]$. The oviposition behaviour of $H$. vicinus Chevrolat on Eucalyptus flower buds has been studied in detail [26], and that of other species is likely to be similar.

\section{Genus Sigastus Pascoe, 1865 (Figure 4)}

Sigastus Pascoe, 1865: 423 [28] (type species, by monotypy: Sigastus fascicularis Pascoe, 1865)

Diagnosis. Body large, oval (Figure 4a), distinctly convex in lateral view (Figure $4 b$ ); rostrum robust and moderately short, dorsoventrally flattened and thickened towards apex in dorsal and lateral view (Figure 4a,b); antennae with funicle 7-segmented but segment 7 densely squamose and very closely appressed (but not fused) to club, club 4-segmented (Figure 4c); procoxae separate; scutellar shield oval; tarsi with onychium distinct, with 2 separate but closely parallel claws (Figure 4d); penis elongate, parallel-sided, apically broadly truncate, tectal plate narrow, temones short; endophallus with internal sclerites reduced (Figure 4e); gonocoxites moderate in length, with apical setae (Figure 4f); spermatheca crook-shaped, narrowed at base, gland elongate, oval (Figure 4g). 

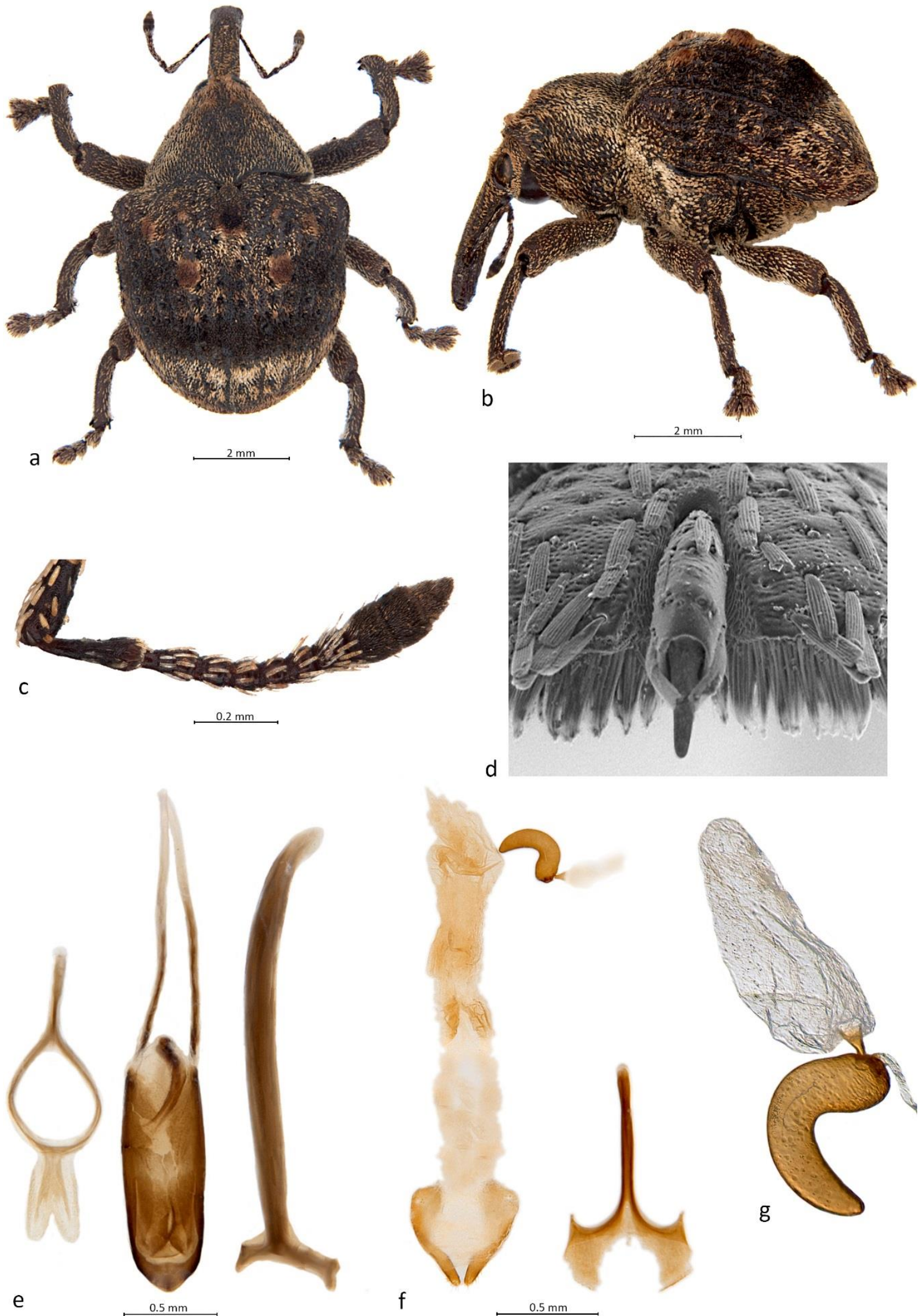

Figure 2. Habitus and diagnostic characters of Haplonyx Schoenherr (H. spencei Gyllenhal): (a) habitus of male, dorsal view; (b) habitus of male, left lateral view; (c) right antenna, male, dorsal view; (d) tarsite 3 with onychium, apical view; (e) genitalia, male, dorsal view; (f) genitalia, female, dorsal view; (g) spermatheca with gland. 

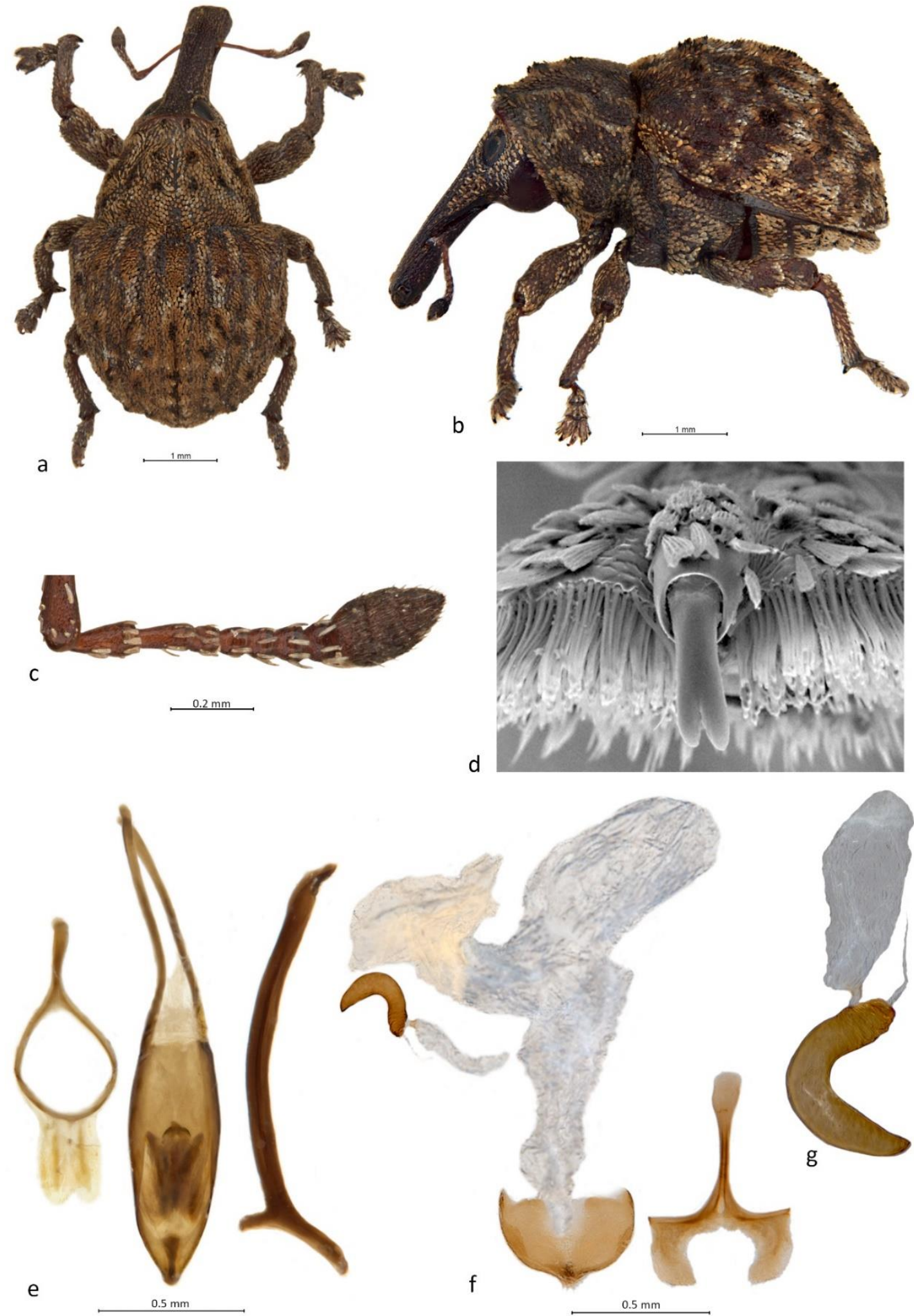

Figure 3. Habitus and diagnostic characters of Haplonyx Schoenherr (H. casuarinae (Lea)): (a) habitus of male, dorsal view; (b) habitus of male, left lateral view; (c) right antenna, male, dorsal view; (d) tarsite 3 with onychium, apical view; (e) genitalia, male, dorsal view; (f) genitalia, female, dorsal view; (g) spermatheca with gland. 

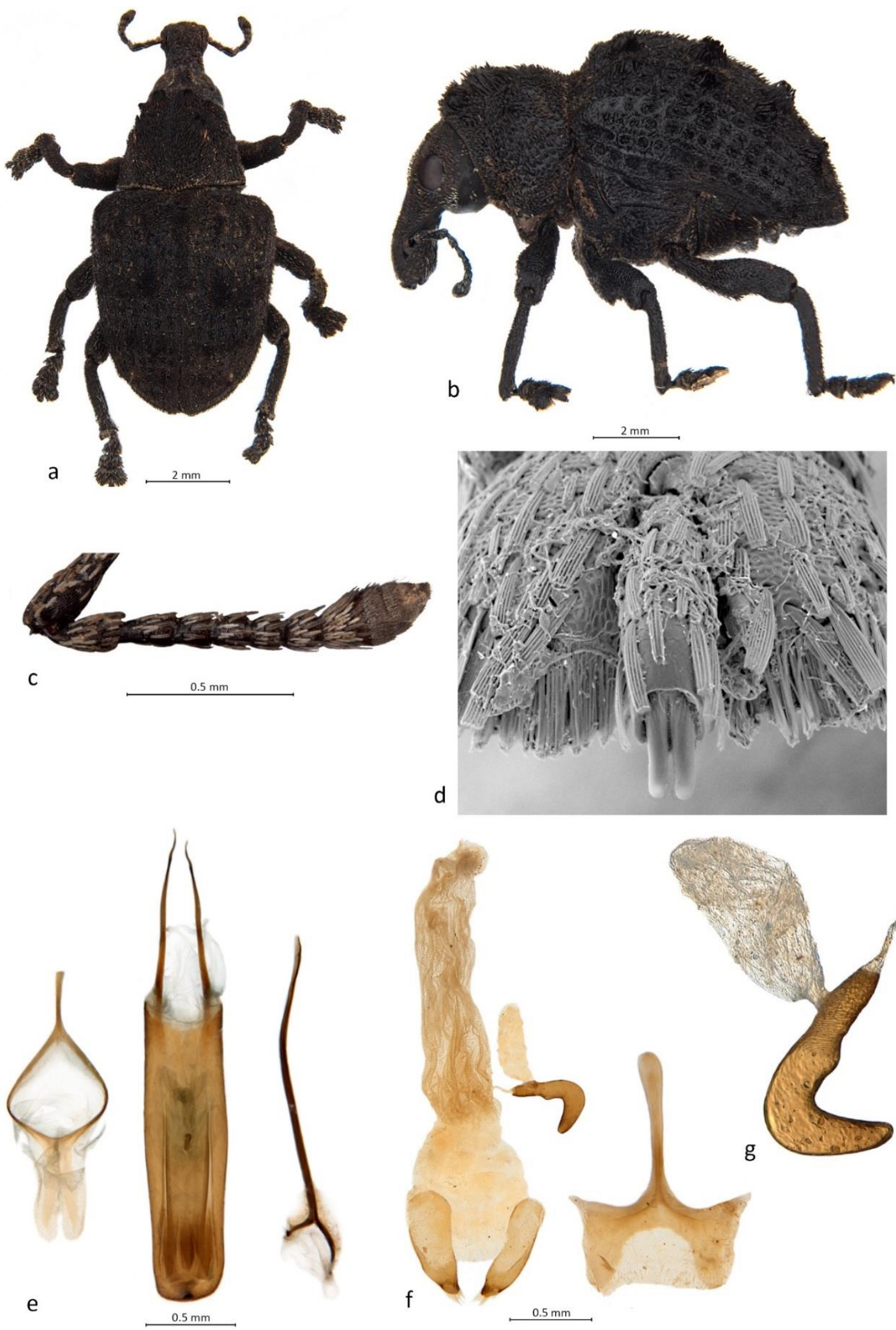

Figure 4. Habitus and diagnostic characters of Sigastus Pascoe (S. fascicularis Pascoe): (a) habitus of male, dorsal view; (b) habitus of male, left lateral view; (c) right antenna, male, dorsal view; (d) tarsite 3 with onychium, apical view; (e) genitalia, male, dorsal view; (f) genitalia, female, dorsal view; (g) spermatheca with gland. 
Remarks. As here constituted, Sigastus is a monotypic genus, including only the type species, S. fascicularis. Sigastus casuarinae was recently transferred to Haplonyx on account of its similarity in vestiture, sculpture and male genitalia to $H$. fasciculatus Boheman [15], despite its tarsal claws being bifid at the apex, not single, and S. fuscodorsalis (Heller) and S. ocularis (Hartmann) are here again classified in their original genus, Menechirus. In the original description of $S$. fascicularis, the claws are described as being connate at the base [28], but Lea noted that they are indeed free along their entire length [11], as they are in Menechirus. From this genus Sigastus differs readily in habitus (size, shape, sculpture), in the antennae (funicle segments 7 appressed to the clubs) and in the male genitalia (the penis parallel-sided and apically truncate, the endophallic sclerites different) and the spermatheca (the collum distinctly elongate). From Kuschelorhynchus it can easily be distinguished on colour, shape, vestiture and male genitalia. Its larvae develop in woody galls on Eucalyptus [29,30].

Genus Zeopus Pascoe, 1872 (Figure 5)

Zeopus Pascoe, 1872: 460 [31] (type species, by monotypy: Zeopus storeoides Pascoe, 1872)

Diagnosis. Body small, oval (Figure 5a), distinctly convex in lateral view (Figure 5b); rostrum long, slender and distinctly curved (Figure 5b); antennae with funicle 6-segmented, segment 7 forming part of club, club thus 5-segmented (Figure 5c); pronotum trapezoidal, at base twice as broad as at apex; procoxae very narrowly separate; elytra $1.2 \times$ longer than wide together, punctate, covered in pale brown to black scales; scutellar shield rounded; tarsi with onychium strongly reduced and concealed in apical cleft of third tarsite, without claws (Figure 5d); penis parallel-sided, apically subtruncate; endophallus spinulose, with double-bowed, asymmetrical internal sclerite (Figure 5e); gonocoxites elongate, with apical setae (Figure $5 \mathrm{f}$ ), bursa copulatrix spinulose, spermatheca crescentic with truncate base, gland mushroom-shaped with distinct funnel-shaped sclerotised base (Figure 5g).

Remarks. The genus is also monotypic, including only the type species, Zeopus storeoides. It was originally described as having no onychia, but there is a very small, short segment hidden in a narrow short cleft of the third tarsites, as is the condition in Cryptoplus. The distinction between Zeopus and Cryptoplus is weak, resting primarily on the greater length and curvature of the rostrum in the former [7]. However, the endophallic sclerites of the penis and the peculiarly shaped spermathecal gland of Zeopus are different from those of all of the Cryptoplus species we examined, and we therefore retain Zeopus as a valid genus. It is widely distributed in the southern parts of Australia, from Western Australia across South Australia (the type locality of Z. storeoides) and Victoria into New South Wales. In spite of this large range, there are no appreciable differences between the specimens and only one species is indicated to exist. It is generally collected on Eucalyptus [7], but its life history appears unknown; the long, strong, curved rostrum of the female suggests that the eggs may be laid into deep plant tissues, probably flower or fruits buds as well.

Genus Menechirus Hartmann, 1901 (Figures 6-10)

Menechirus Hartmann, 1901: 278 [32] (type species, by original designation: Menechirus oculatus Hartmann, 1901); Klima, 1935: 1 [33] (in Trigonocolinae); Alonso-Zarazaga \& Lyal, 1999: 208 [6] (in Trigonocolini); Caldara et al., 2014: 605-606 [1] 

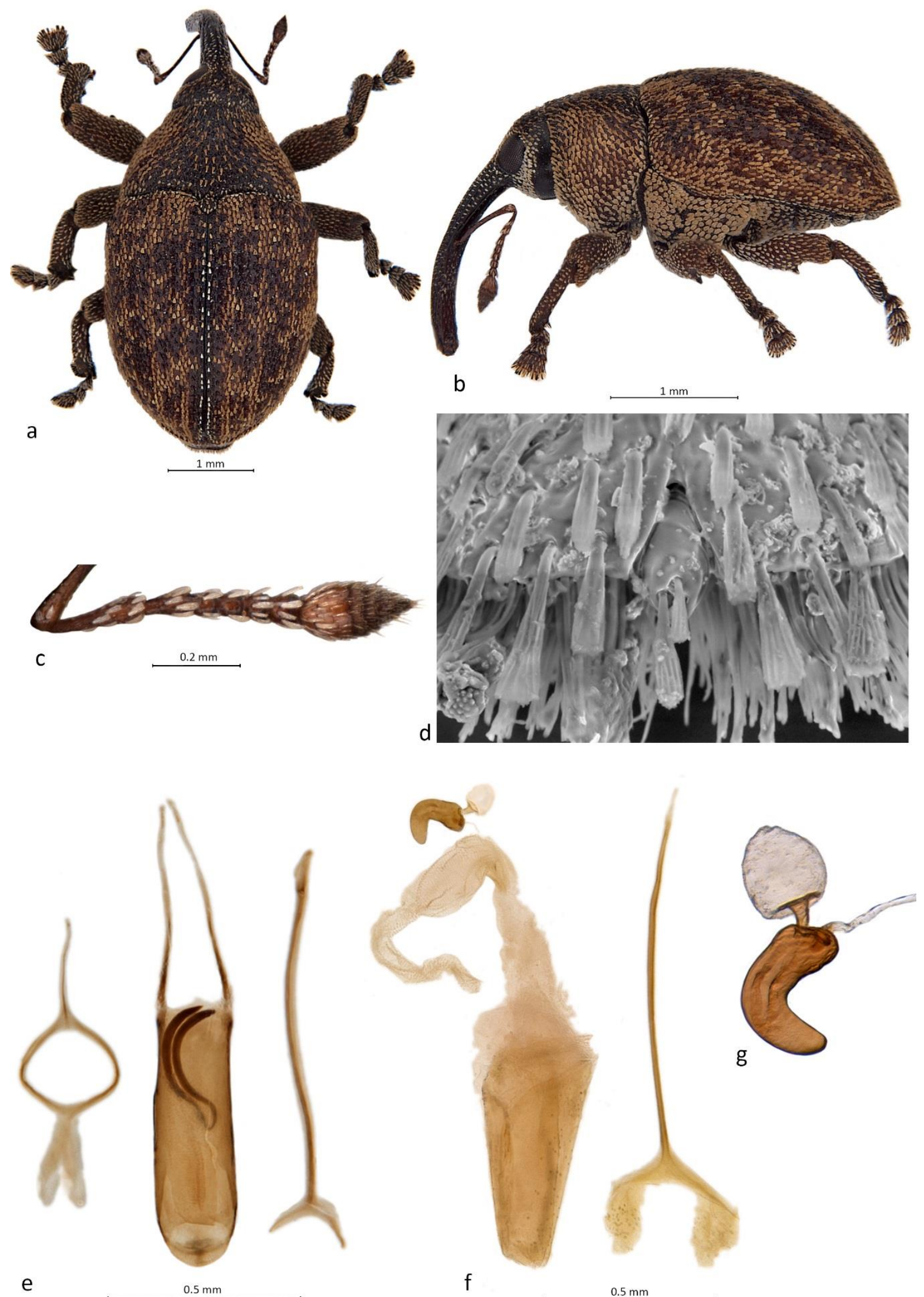

Figure 5. Habitus and diagnostic characters of Zeopus Pascoe (Z. storeoides Pascoe): (a) habitus of male, dorsal view; (b) habitus of male, left lateral view; (c) right antenna, male, dorsal view; (d) tarsite 3 with onychium, apical view; (e) genitalia, male, dorsal view; (f) genitalia, female, dorsal view; (g) spermatheca with gland. 
Diagnosis. Body short and wide, vestiture with scattered brown and white scales forming more or less distinct patterns on pronotum and elytra; rostrum robust, relatively short and straight, dorsoventrally flattened, widening apicad in dorsal view but narrowing apicad or substraight in lateral view, with distinct dorsolateral and sometimes dorsomedian carinae, scrobes deep, narrow, running onto venter of rostrum but not meeting; antennae with funicle 7 -segmented, segment 7 usually clearly distinct from club, club 4-segmented; pronotum strongly convex to tumescent, with small anterior and larger central pair of low tubercles, strongly patterned with dark and pale scales, the latter usually forming one or two transverse arcs; procoxae narrowly separate; elytra short and broad, disc with a number of paired tubercles forming a broad $V$, laterally with a large, dark subtriangular patch; scutellar shield ogival to oval; tarsi with onychium as long as tarsite 3 but protruding from it, narrow, with fine, subparallel or slightly divergent claws; abdominal ventrites 1 and 2 equal in length, almost $2 \times$ longer than 3 and 4, ventrite 5 with a pair of one or two long setae near caudal margin; penis narrowly navicular with acutely pointed apex, temones about as long as penis body, simple; endophallus with a pair of narrow long internal sclerites, sometimes fused at apex or absent; gonocoxites narrowly triangular to faintly sinuate, apex broadly subtruncate with several stiff setae, styli absent, bursa copulatrix and oviduct membranous, spermatheca shortly crescentic, thick, undifferentiated, gland shortly to moderately elongate, arising from short, lightly sclerotised, funnel-shaped duct, sternite VIII short and broad, bladal part with large desclerotised median area, margin fringed with several stiff setae, apodeme about as long as bladal part.

Remarks. As here constituted, Menechirus contains two previously described species, M. oculatus and M. fuscodorsalis, and we add another three new ones below. The claws of Menechirus were not mentioned in its original description [32] nor in the later description of M. fuscodorsalis [34], but in a footnote accompanying the latter Heller wrote that "Menechirus represents a Haplonyx with two unguiculi" and suggested placing it in the same group (as "Haplonicidae"). Menechirus was recently merged into Sigastus [15], mainly on the basis of their similar claw structure, although the differences in vestiture, length of rostrum and antennae and structure of the penis between their type species were noted. From our more detailed study of all available species and material of these taxa, including of the genitalia, we conclude that there are sufficient differences between Menechirus and Sigastus (including the hostplants) to regard them as different genera, and we consequently here reinstate Menechirus as a valid genus. It differs from Sigastus in its shorter, squatter body, larger rostrum, patterned pronotum and elytra, the free funicle segments 7 (not appressed to the club), the pointed penis with a pair of long, narrow endophallic sclerites, the shorter ovipositor and a short to absent collum of the spermatheca. In its tubercle arrangement on the elytra and its vestiture it is most similar to Kuschelorhynchus, from which it differs in its smaller size, much weaker dorsal sculpture and flatter, more wedge-shaped rostrum in lateral view as well as in its male and female genitalia. It develops in the fleshy flower and fruit buds of Syzygium and possibly Rhodomyrtus (Myrtaceae).

\subsection{Key to the Species of Menechirus}

1. Elytra with sutural interstriae jointly raised to about middle of elytral length; pronotum with central pair of tubercles small, low, not jointly elevated; dorsolateral carinae of rostrum as high as area between dorsomedian carinae; funicles with segment 7 closely appressed to club; clubs short, thick $(2 \times$ longer than wide); dorsal colour pattern variable (Australia, Northern Territory) M. fuscodorsalis Heller

- Elytra with sutural interstriae not or only faintly and shortly elevated behind scutellar shield; pronotum with central pair of tubercles large, elevated on a joint hump; dorsolateral carinae of rostrum lower than area between dorsomedian carinae; funicles with segment 7 distinctly separate from club; clubs mostly longer than wide

2. Body length $>5 \mathrm{~mm}$; pronotum with large pair of central tubercles and pale setae distributed widely on disc and sides; sutural interstriae in male with pale, flat scales behind scutellar shield 
- $\quad$ Body length $<5 \mathrm{~mm}$; pronotum with small pair of central tubercles and pale setae forming one to two narrow bands arching from bases across central tubercles; sutural interstriae in male with short, V-shaped patch of pitch-black, erect scales behind scutellar shield ....

3. Rostrum with distinct dorsomedian carinae; pronotum with broad band of black setae across base but without pairs of small, glabrous dots (Australia, northern Queensland) M. howdenae sp. $\mathrm{n}$.

- $\quad$ Rostrum without dorsomedian carinae defined; pronotum without black setae across base but with two pairs of small, glabrous (non-squamose) dots, one opposite striae 3 and the other opposite humeri (New Guinea)

4. Pronotum with black scales limited to a pair of subtriangular patches laterally of median tubercles; tubercles low, small; clubs short, less than $2 \times$ longer than wide; elytra with creamy and brown scales admixed, black scales forming fragmented band across middle (Papua New Guinea) M. oculatus Hartmann

- $\quad$ Pronotum with black scales forming larger irregular macula laterally of median tubercles; tubercles high, large; clubs elongate, more than $2 \times$ longer than wide; elytra with creamy, brown and black scales largely segregated into patches forming a variegated pattern (Indonesia, West Papua) Menechirus sp.

5. Pronotum with two pairs of small black tubercles, one in middle and one on anterior border, and one pale band curving from behind median tubercles to basal corners; elytra with four pairs of tubercles on anterior slope well developed; pale patch on elytral declivity well demarcated, narrow M. parryi sp. n.

- $\quad$ Pronotum with one pair of small black tubercles in middle and two pale bands curving from before and behind median tubercles to basal corners; elytra with four pairs of tubercles on anterior slope poorly developed, except for posterior one on interstriae two; pale patch on elytral declivity poorly demarcated, broader M. mundus sp. n.

\subsection{Revision of the Species of Menechirus}

Menechirus oculatus Hartmann, 1901 (Figure 6)

Menechirus oculatus Hartmann, 1901: 279 [32]; Klima, 1935: 1 [33]; Pullen et al., 2014: 458 [15].

Diagnosis. Body short, oval, 5.5-5.8 mm long, 3.5-4.0 mm wide; moderately densely covered with pale brown and black scales interspersed with few white ones, forming distinct pattern on head, pronotum and elytra (Figure 6a); rostrum slightly longer than pronotum, robust, apically broadened in dorsal view, in lateral view straight, flattened (Figure 6b), dorsomedian carinae indistinct, slightly diverging anteriad, higher than dorsolateral ones; antennae slender, with club robust, ca. $2.5 \times$ broader than funicle (Figure 6c); pronotum in centre of disc with pair of large, low, blunt tubercles covered with dark erect scales along base, with 2 pairs of small denuded spots; scutellar shield inversely ogival, flat, sparsely squamose; elytra as broad across humeri as long, with irregular broad dark transverse band behind humeri; tibiae with premucro much smaller than uncus, tarsi with claws slightly divergent (Figure 6d); penis with sides subparallel, apex broadly triangular, temones longer than penis body, endophallus with internal sclerite large, thick, V-shaped (Figure 6e); gonocoxites narrowly triangular (Figure 6f), spermathecal gland large, drop-shaped (Figure 6g).

Material examined (1 $\sigma^{7}, 3$ \%). 1 q: “Mt Lamington / N. E. Papua / 1300 to 1500 feet / C. T. McNamara // ANIC / Image / / / / Menechirus / oculatus Hartmn / (ex description) / det. R. G. Oberprieler 2014"; 1 q: same label and data except for identification label; $10^{7}$ : same data but on handwritten label and without identification label.

Distribution. Eastern Papua New Guinea (Madang and Oro provinces) as known; probably more widespread.

Hostplants. None recorded but probably Syzygium (Myrtaceae), the host genus of all other Menechirus species. 


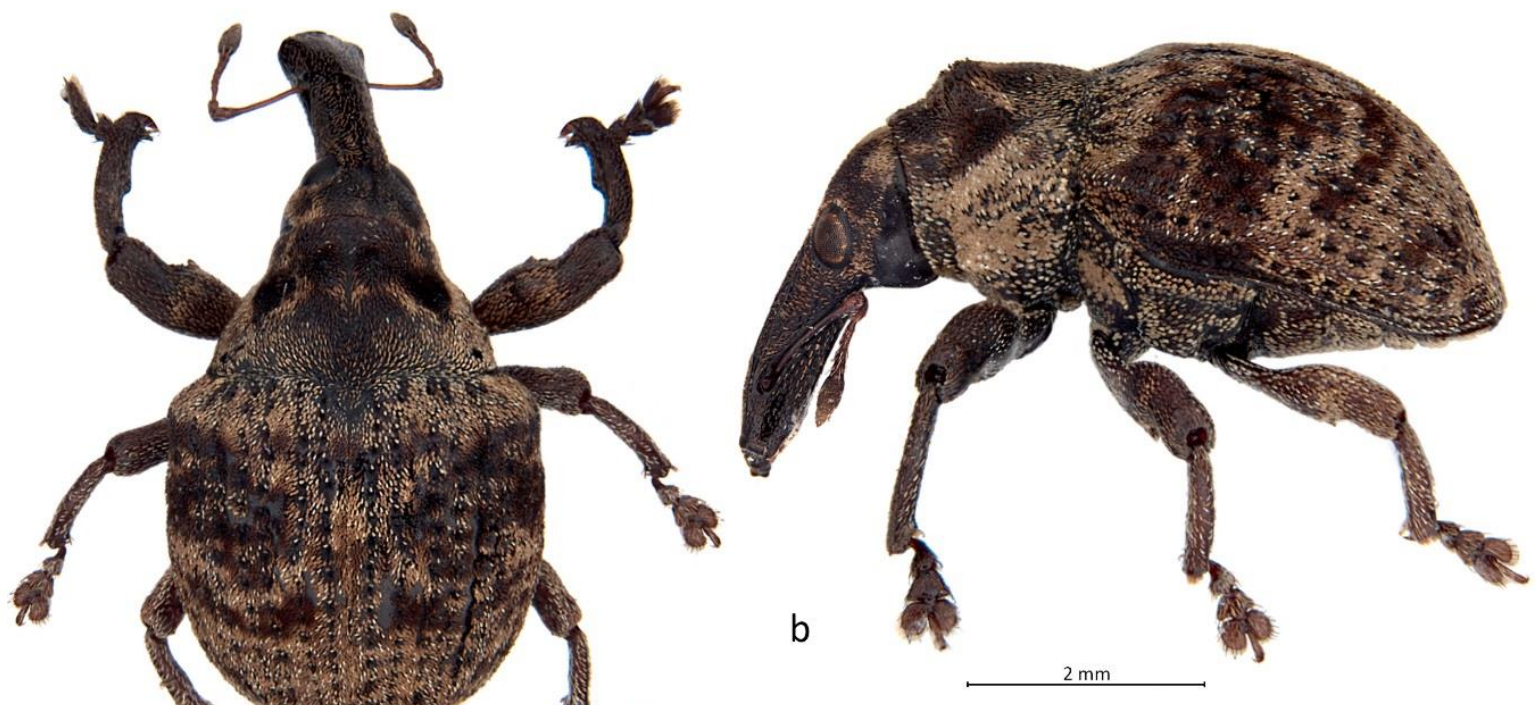

a
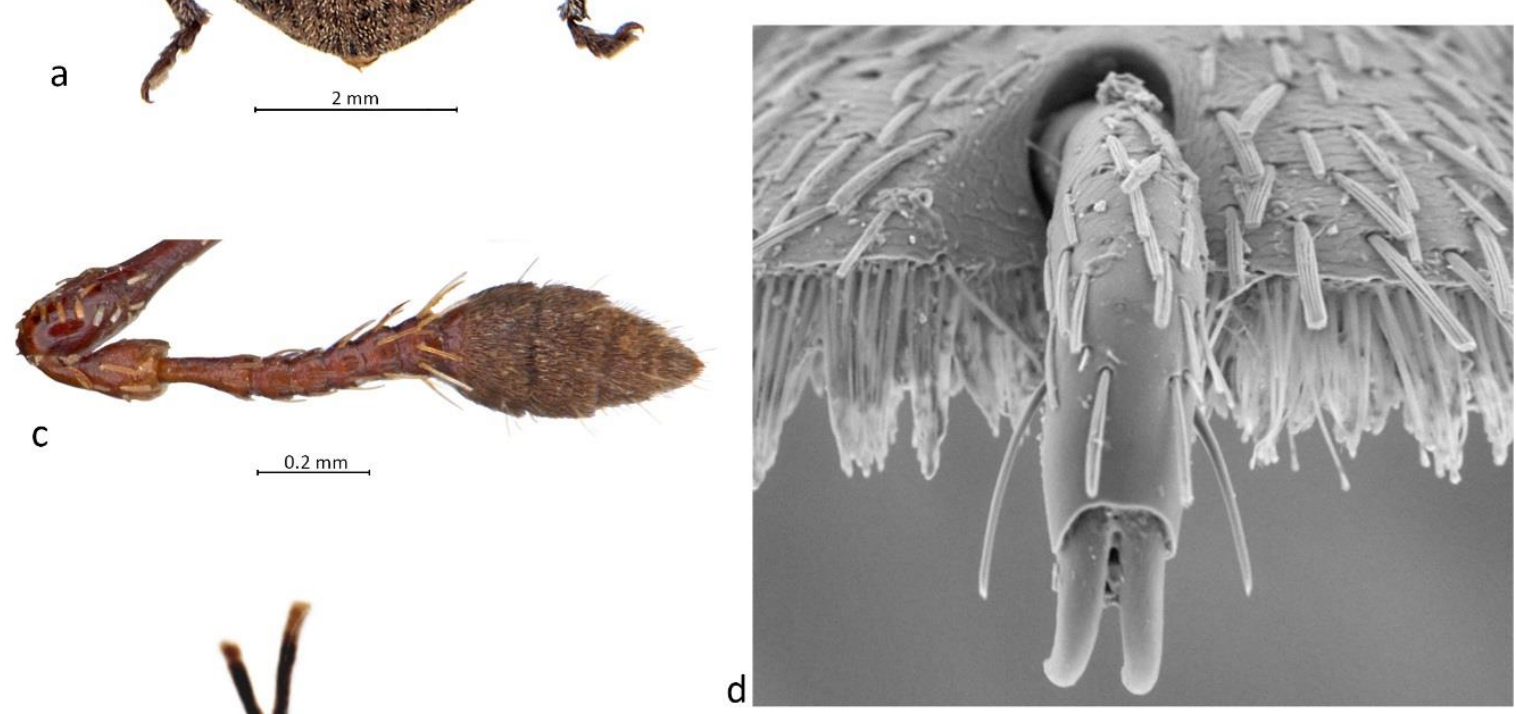

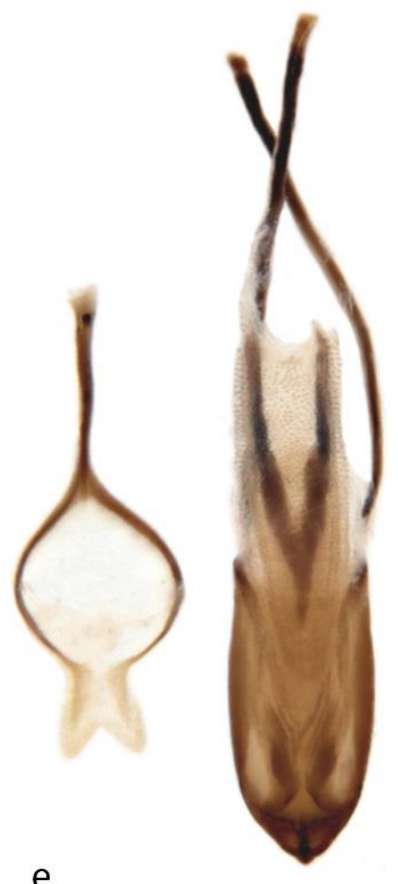

e

$0.5 \mathrm{~mm}$

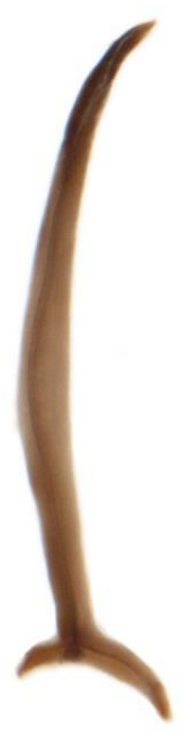

f

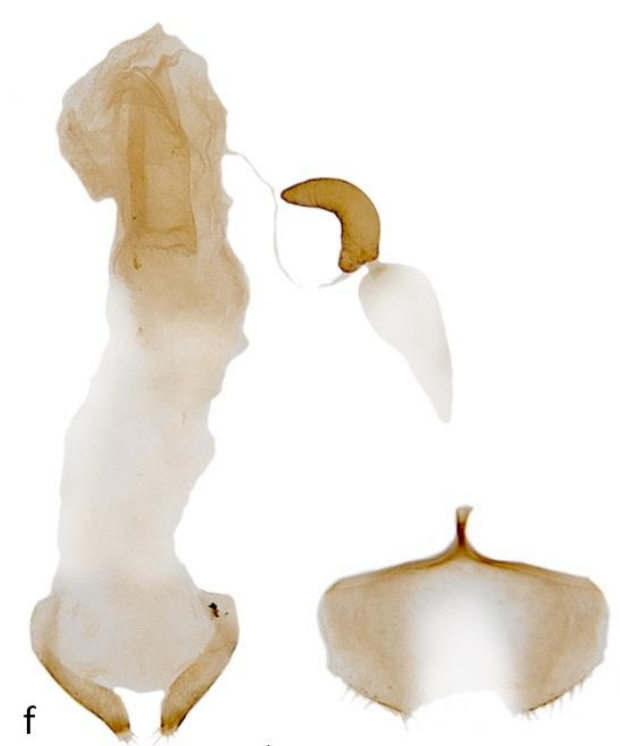

$1 \mathrm{~mm}$

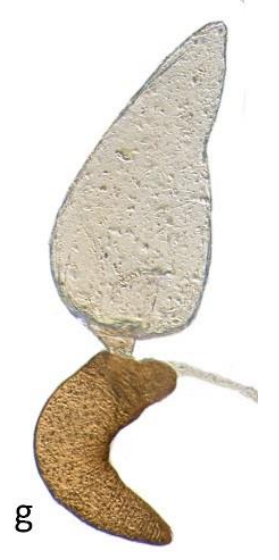

Figure 6. Habitus and diagnostic characters of Menechirus oculatus Hartmann: (a) habitus of male, dorsal view; (b) habitus of male, left lateral view; (c) right antenna, male, dorsal view; (d) tarsite 3 with onychium, apical view; (e) genitalia, male, dorsal view; (f) genitalia, female, dorsal view; (g) spermatheca with gland. 
Remarks. This species was described from Bongu in the Madang province [32] and appears to be the only species of Menechirus recorded from New Guinea so far. However, another species is represented in the ANIC by a single female (missing some legs), collected in September 1944 by Cari Mohr at Sansapore in West Papua. It differs from M. oculatus inter alia in having larger pronotal protuberances, a larger and more irregular dark macula next to them (not small, round, 'eye'-like as in M. oculatus), more elongate antennal clubs, a more strongly sculptured rostrum and a more variegated pattern of elytral scales. Menechirus oculatus can be distinguished from all other known species by its pair of subtriangular dark pronotal maculae, which appear eye-like and for which it was named. Among the Australian species, M. oculatus is most similar to M. howdenae, differing as in the key above and also in its long, V-shaped endophallic sclerite (Figure 6e). As Syzygium is a very diverse genus in New Guinea, it is likely that more species of Menechirus occur in New Guinea.

Menechirus fuscodorsalis Heller, 1922 (Figure 7)

Menechirus fuscodorsalis Heller, 1922: 556 [34]; Klima, 1935: 1 [33]

Sigastus fuscodorsalis (Heller): Zimmerman, 1994: 677 [12]; Juniper \& Britton, 2010: 300 [30];

Caldara et al., 2014: 606 [1]; Pullen et al., 2014: 191 [15]

Sigastus tropicus Lea, 1928: 103 [11]; Zimmerman, 1994: 677 [12] (syn.); Pullen et al., 2014: 191 [15]

Diagnosis. Body short, oval in dorsal view (Figure 7a), strongly convex in lateral view (Figure 7b), 5.2-8.0 mm long, 2.5-5.5 mm wide; densely covered with pale brown, black and white scales, brown and black ones forming pattern, white ones interspersed, pronotum often with pale triangular median macula laterally bordered by broad or divided dark band and elytra usually with opposite pale parabolic basal median macula on interstriae 1-3, similarly bordered by broad dark band, but colour pattern very variable; rostrum robust, as long as pronotum, flattened in apical half, broadest at apex, in posterior half with dorsolateral carinae distinct, dorsomedian ones obscured by scales (Figure 7a,b); antennae reddish in colour, funicle 7-segmented, club 4-segmented (Figure 7c); pronotum in centre of disc with pair of small, short tubercles covered with black, erect scales (Figure 7a); scutellar shield small, ogival, squamose; femora with very small ventral teeth or angulations, tibiae with large, subequal uncus and premucro (both smaller on mesotibiae), tarsi with claws subparallel (Figure 7d); penis narrowly navicular, apically narrowed, temones as long as penis body, endophallus spinulose with paired, tube-like internal sclerites (Figure 7e); gonocoxites short, apically setae, bursa copulatrix spinulose (Figure 7f), spermatheca weakly crescentic with rounded base, gland elongate, apically narrowed (Figure 7g).

Material examined (43 $\sigma^{7}, 44$ ᄋ). $1 \sigma^{7}$ : “Darwin / G.F. Hill / Sigastus / tropicus / Lea / Det '75 by E.C. Zimmerman / / o"; 1 o: “Darwin / G.F. Hill / / in fruit of / Eugenia / suborbicul / -aris. / / Menechirus / fuscodorsalis / Heller / Det. "75 E.C. Zimmerman / q"; 1 \%: "Darwin / G.F. Hill / / १”; 2 o", 1 \%: “Darwin, N.T. / 17/12/50 // K.G. Brown. / / Col. 20/11 / EM. 17/12 / Host / Wild Apple / Eugenia / / F.H. UTHER BAKER / BEQUEST / 1992 / / Sigastus tropicus / Lea / cv. SAM / det. F.H. Uther Baker"; 19: "Humpty Doo, N.T. / 30.12.53 / I.D. Crawford / / G1 / / Ento. Section / N.T.A. Darwin / / q"; 1 q: “Humpty Doo, N.T. / 30.12.53 / I.D. Crawford / / Found on rice / / Genus ? near / Sigastus / CURCULIONIDAE / Haplonycinae / Det. T.G. Campbell / / q"; $10^{\text {: }}$ : same data except for label "Found on rice"; 1 o", 1 q: "Br. Ck [Brock's Creek] / 11/12/31 / T.G.C[ambpell]."; 1 ơ: "Tortilla Flats, N.T. / 2nd Nov. 1967 / EMG. 11-12. Nov.1967 / Coll. C.S. Li // Found on / Eugenia / suborbicularis / / Haplonyx ? / HAPLONYCHINAE / Ento. Section / N.T.A. Darwin // o'”; 1 \%: “N. Territory / Dec. 1950 / W.F. Nixon-Smith / / On Wild Apple / (Eugenia sp.) // COM. INST. ENT. /COLL. No. 12205 // Genus ? near / Sigastus-not in BM / Det. G.A.K. Marshall //

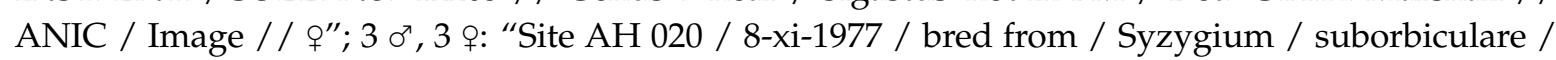
J. Waldeck"; 1 ơ: “12.25S 132.58E / 1 km N of Cahills Crossing / (East Alligator River), N.T. / 31.x.72, at light, E. Britton / / o"; 1 \%: "12.23S 132.56E / 7 km NW by N of / Cahills Crossing, / (East Alligator

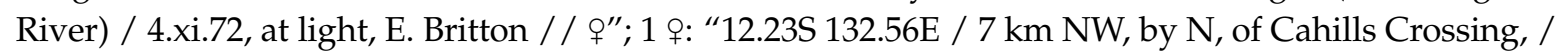

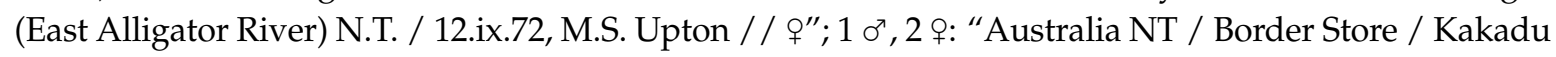


NP / 2 Dec 2003 G. Bellis / / Emerged from / fruit/seed of / Syzygium / suborbiculare / / ANIC / Image / / Sigastus / fuscodorsalis / det. R.G. Oberprieler 2017 / / ф"; 1 ơ: "Pickertaramoor / Melville Island / 19.ii.1981 N.T. / A. Allwood. // Ex fruit of / Eugenia / armstrongii / Sigastus / tropicus / Lea / Det. '82 E.C. Zimmerman // ơ"; 1 ơ, 1 o: "Pickertaramoor / Melville Island, N.T. / 20.xii.1976 / A. Allwood. / / bred from Szigium [sic] / suborbicularis [sic] / / Sigastus / tropicus / Lea / Det. '77 by E.C. Zimmerman / / o"”; 1 o": "11.01 S 136.45 E / Rimbija Is. / Wessels Islands / NT / 3-14 Feb. 1977 / T.A. Weir / / Compared with / HOLOTYPE E.C.Z. / Menechirus / fuscodorsalis / Heller [on pink card] / / $0^{\text {" }}$; $10^{7}$ : same data except pink identification label, instead "Specimen / figured / ECZ / Sigastus / fuscodorsalis / (Heller) / Det. E.C. Zimmerman // $\mathrm{o}^{7 \prime \prime} ; 5$ o, 4 \%: same data but no identification labels;

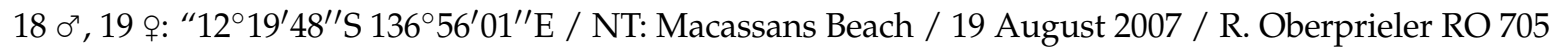
// Sigastus fuscodorsalis / det. R. Oberprieler 2007 / on Syzygium"; $50^{\top}, 2$ o: “12 $16^{\circ} 43^{\prime \prime} \mathrm{S} 136^{\circ} 53^{\prime} 46^{\prime \prime} \mathrm{E}$ / NT: Gove, Shady Creek / 25 Aug 2007 / R. Oberprieler RO 719 // Menechirus fuscodorsalis / det. R. Oberprieler 2017 / on Syzygium / suborbiculare"; $10^{\prime \prime}, 4$ \%: "12 $12^{\circ} 9^{\prime} 40^{\prime \prime} \mathrm{S} 136^{\circ} 46^{\prime} 48^{\prime \prime} \mathrm{E} / \mathrm{NT}$ : Gove, Cape Wirrawoi / 26 Aug 2007 / R. Oberprieler RO 719".

Distribution. Common and seemingly widespread in coastal areas and along rivers in the Northern Territory, where its hostplant occurs, but not recorded from northern Queensland and northern Western Australia, where this host also grows; not evidently established in the Philippines, from where it was described.

Hostplants. Mainly Syzygium suborbiculare (Myrtaceae), the larvae developing in the fleshy flower buds and fruits; apparently also in fruits of Syzygium armstrongii but frequency and extent of this host association to be determined.

Remarks. This is the largest species of Menechirus known. It was originally described from Luzon, Philippines, based on seemingly a single specimen reared from the fruit ("seeds") of Syzygium suborbiculare imported from Darwin, Australia [12,34]. Lea [11] was vague about the type series of the synonym Sigastus tropicus, citing the localities as "Darwin (G.F. Hill)" and "Cairns district (A.M. Lea)" and referring to the type, "a second specimen, from Darwin" and as a specimen from Cairns. He thus evidently had two additional specimens from Darwin collected by G.F. Hill (see Material examined). The specimen from Cairns represents a different species, described as M. howdenae below. The pronotum and elytra of $M$. fuscodorsalis usually have a distinct pattern of opposite subtriangular maculae of pale scales bordered by a broad band of darker ones, but specimens with different or no patterns occur among ones so patterned. 

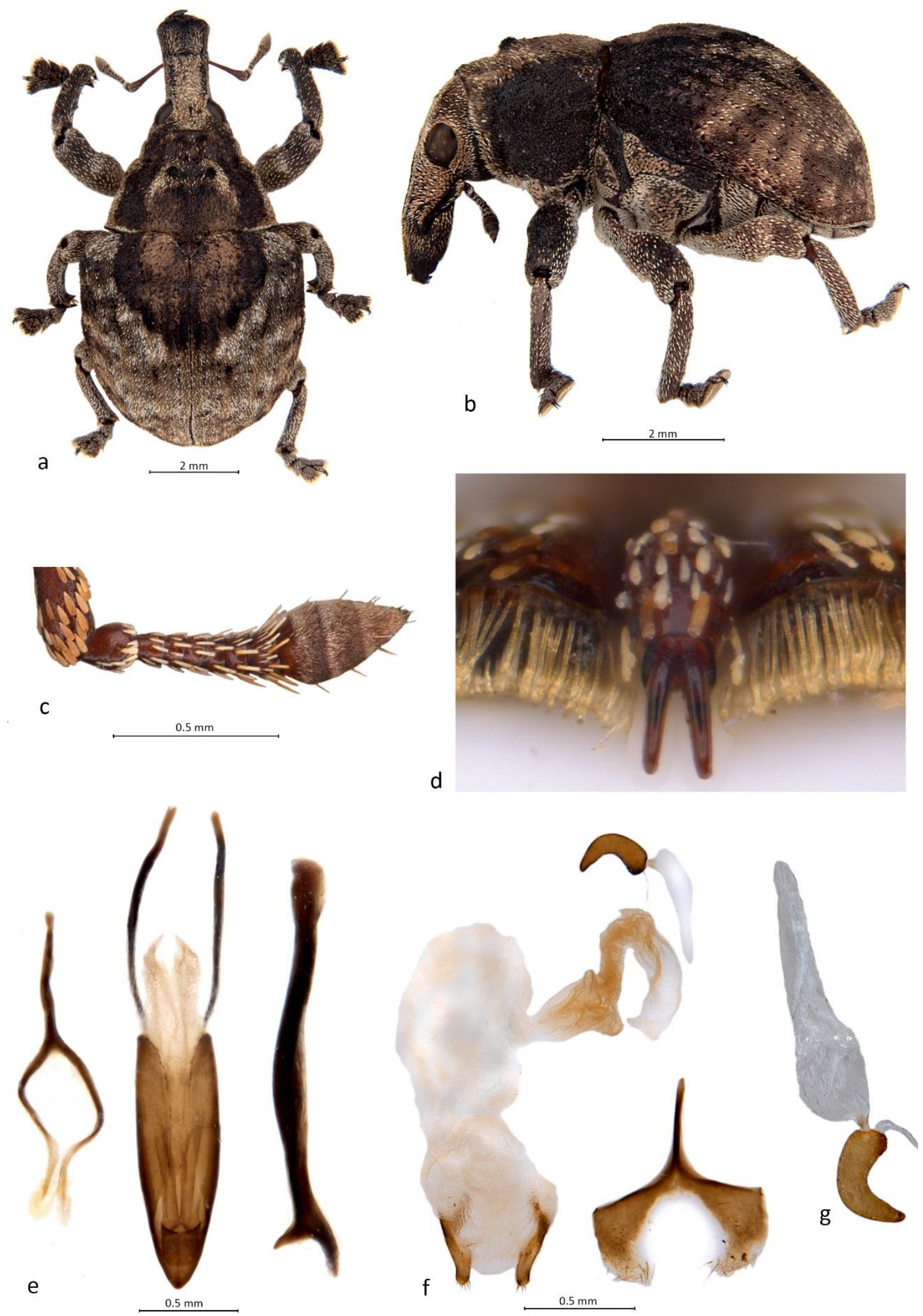

Figure 7. Habitus and diagnostic characters of Menechirus fuscodorsalis Heller: (a) habitus of male, dorsal view; (b) habitus of male, left lateral view; (c) right antenna, male, dorsal view; (d) tarsite 3 with onychium, apical view; (e) genitalia, male, dorsal view; (f) genitalia, female, dorsal view; (g) spermatheca with gland. 
Menechirus howdenae Jennings \& Oberprieler, sp. n. (Figure 8)

Description: Shape. Body very short, ovoid, length 5.0-6.4 mm in both sexes (holotype $6.4 \mathrm{~mm}$ ), width ca. $0.8 \times$ length (Figure 8 a), distinctly convex in lateral view (Figure 8 b). Colour and vestiture. Body densely covered with pale brown to black scales (with few white ones scattered in between); head with pale scales interrupted by a dark broad median stripe and a pair of similar stripes behind dorsal half of eyes; pronotum in male largely with black scales except for narrow curved band of pale scales laterally, in female more uniformly pale; elytra largely with pale scales except for irregular broad dark band curving from interstria 4 in about middle of disc towards humerus (Figure 8a); rostrum mostly with dark scales; legs and underside with pale ones (Figure 8a). Rostrum. Short (about $1.15 \times$ longer than pronotum in male, $1.25 \times$ in female), robust, straight, dorsoventrally flattened, apically broadened in dorsal view, distal half dorsally coarsely punctate, proximal half with pairs of distinct, thick dorsomedian and dorsolateral carinae, the latter lower than the former (Figure 8a,b). Eyes. Subcircular in outline, slightly convex but not protruding (Figure $8 \mathrm{~b}$ ). Antennae. Inserted in apical third of rostrum; scapes reaching to below anterior margin of eye in repose; funicles with segments 1 and 2 subequal, each $2 \times$ longer than each of segments 3 to 7 ; clubs elongate, $2.5 \times$ longer than broad, finely pubescent (Figure 8c). Pronotum. Trapezoidal in shape, $1.8 \times$ wider at base than at apex; disc tumescent, culminating in a pair of blunt, elongate, broadly separated central tubercles carrying a tuft of black erect scales, in male with band of pale scales curving laterad from tubercles towards anterior margin (Figure 8a), in female completely covered with pale scales laterally; surface shallowly punctorugulose. Scutellar shield. Roundly triangular to cordiform, margins bluntly rounded, sparsely covered with elongate narrow scales. Elytra. $1.8 \times$ longer than pronotum, joint width $1.3 \times$ length, slightly wider than base of pronotum; humeri broadly rounded, slightly protruding (Figure $8 a, b$ ). Legs. Femora with 2 unequal ventral teeth, anterior one very small; tibiae with premucro smaller than uncus; tarsi with claws slightly divergent (Figure $8 d$ ). Genitalia. Penis narrowly elongate $(6 \times$ longer than broad), sides subparallel, apically narrowed, pointed, temones slightly shorter than penis body, endophallus with long, hairpin-shaped internal sclerite (Figure 8e); gonocoxites narrow, apically bluntly rounded, setose (Figure $8 \mathrm{f}$ ), bursa copulatrix spinulose, spermatheca thick, right-angled, gland moderately long, elongate oval, narrowing apicad (Figure 8g).

Material examined (9 $\odot^{7}, 7$ \%). Holotype, ơ: "QLD: Garradunga, Polly / Creek / 11 Nov 2003 / J. Hasenpusch / / ANIC / image / / $\sigma^{x} / /$ HOLOTYPE / Menechirus howdenae / Jennings \& Oberprieler, 2018" (ANIC). Paratypes (all labelled "PARATYPE / Menechirus howdenae / Jennings \& Oberprieler, 2018”): $1 \sigma^{7}, 2$ o: same data as holotype; $60^{\prime \prime}, 5$ o: “Julatten, QLD / em 27 Jan. 1987 / A.T. Howden / / Ex mature / fruit of / Syzygium sp. // $\sigma^{7} / q^{\prime \prime} ; 1 \sigma^{7}:$ "Ex Rhodomyrtus / macrocarpus / Mission Beach / 24.9.54 WAS / / D.P.I. QLD / / 701 / $\sigma^{7 \prime \prime}$.

Distribution (Figure 13). North-eastern Queensland.

Hostplants. Syzygium species, seemingly also Rhodomyrtus macrocarpus (Myrtaceae).

Derivation of name. The species is named for the late Anne Howden (1927-2016) of Ottawa, Canada, who collected the majority of the type specimens of this species and also made important other contributions to the knowledge of the Australian weevil fauna, in particular to the biology of the iconic tribe Amycterini, and to oviposition behaviour in weevils in general.

Remarks. This is one of two species thus far known to occur in Queensland. It is most similar to the New Guinean M. oculatus, of a similar size and with similar markings on the prothorax and elytra but with a shorter and rounder body shape. It further differs from M. oculatus in having distinct dorsomedian carinae in the basal half of the rostrum, a broad band of black setae across the base of the pronotum, the central pronotal tubercles larger and the endophallic sclerite of the penis narrowly hairpin-shaped, not broadly V-shaped as in M. oculatus. In the female terminalia, M. howdenae has broader gonocoxites, a longer sternite VIII and a more rectangular spermatheca. From the smaller M. parryi and M. mundus, $M$. howdenae also differs conspicuously in the lack of black scales behind the scutellar shield in the male, the less ornate pronotal and elytral colour patterns, the divergent claws and the shape of the endophallic sclerite of the penis. 

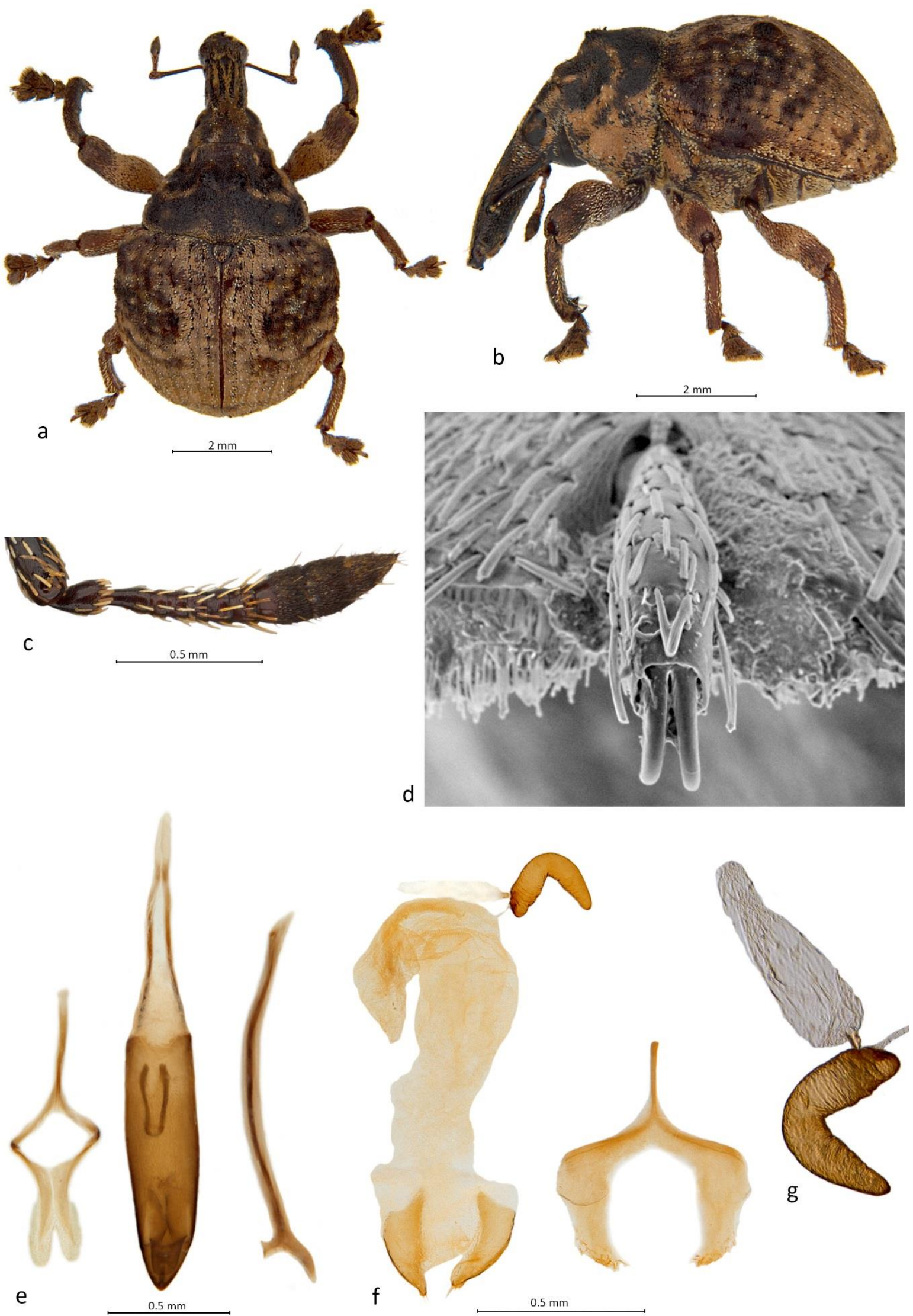

Figure 8. Habitus and diagnostic characters of Menechirus howdenae sp. n.: (a) habitus of male, dorsal view; (b) habitus of male, left lateral view; (c) right antenna, male, dorsal view; (d) tarsite 3 with onychium, apical view; (e) genitalia, male, dorsal view; (f) genitalia, female, dorsal view; (g) spermatheca with gland. 
Menechirus parryi Jennings \& Oberprieler, sp. n. (Figure 9)

Sigastus new species 1: Juniper \& Britton, 2010: 300 [30]

Description: Shape and size. Body short, ovoid in dorsal outline, length $3.4-4.6 \mathrm{~mm}$ in both sexes (holotype $4.1 \mathrm{~mm}$ ), width ca. $0.7 \times$ length (Figure 9a), strongly convex in lateral view (Figure 9b). Colour and vestiture. Body densely covered with pale brown to black scales (with few white scales scattered in between); head with pale scales except two pairs of large indistinct brown patches dorsolaterally and laterally behind eyes; pronotum with brown scales except for 2 narrow, transverse bands of pale scales arching from sides of base across anterior half of disc; elytra typically with 3 similar but opposite arches from bases of interstriae 2, 4 and 6 across elytral disc, in male also with a median patch of black scales behind scutellar shield; sides with black scales, ventrites and parts of legs with pale ones (Figure 9a). Rostrum. Short (about $1.2 \times$ longer than pronotum in male, $1.3 \times$ in female), robust, straight, dorsoventrally flattened, apically broadened in dorsal view, distal third dorsally coarsely shallowly punctate, proximal two-thirds indistinctly rugose with faint median carina and indistinct dorsolateral carinae, no dorsomedian ones (Figure 9a,b). Eyes. Broadly ovoid in outline, slightly convex but not protruding (Figure 9b). Antennae. Inserted in apical third of rostrum; scapes not reaching to below anterior margin of eye in repose; funicles with segments 1 and 2 subequal, each almost $2 \times$ longer than each of the segments 3 to 7 ; clubs shortly elongate, $2 \times$ longer than broad, finely pubescent (Figure 9c). Pronotum. Trapezoidal in shape, $2 \times$ wider at base than at apex; disc tumescent, culminating in a pair of low, blunt, broadly separated central tubercles with a tuft of black scales, a similar but smaller pair of tubercles on anterior margin and another pair of indistinct ones laterally, the posterior curved band of pale scales passing just behind central tubercles and the anterior, medially interrupted band just behind lateral tubercles (Figure 9a). Scutellar shield. Roundly subtriangular, sparsely covered with long, suberect scales. Elytra. $2 \times$ longer than pronotum, joint width only slightly less than length, wider than base of pronotum; interstriae 1 slightly elevated at base, interstriae 2 with single large tubercle with tuft of erect brown scales in middle of length, interstriae 3 with 2 more anteriorly placed, similarly tufted tubercles, interstriae 5 with similar pair of smaller tubercles; single tubercle of interstriae 2, posterior tubercle of interstriae 3 and tubercle 1 of interstriae 5 connected by a pale band forming a conspicuous V (Figure 9a). Legs. Femora with 2 unequal ventral teeth, anterior one minute; tibia with premucro much smaller than uncus; tarsi with claws parallel, very close together (Figure $9 \mathrm{~d})$. Genitalia. Penis elongate $(4.5 \times$ longer than broad), sides subparallel, apically narrowed, pointed, temones as long as penis body, endophallus spinulose, without distinct internal sclerites (Figure 9e); bursa copulatrix with two long bands of dense, elongate spicules (Figure 9f), spermatheca crescentic, about evenly thick, gland large, oval, broadly rounded apically (Figure 9g). 

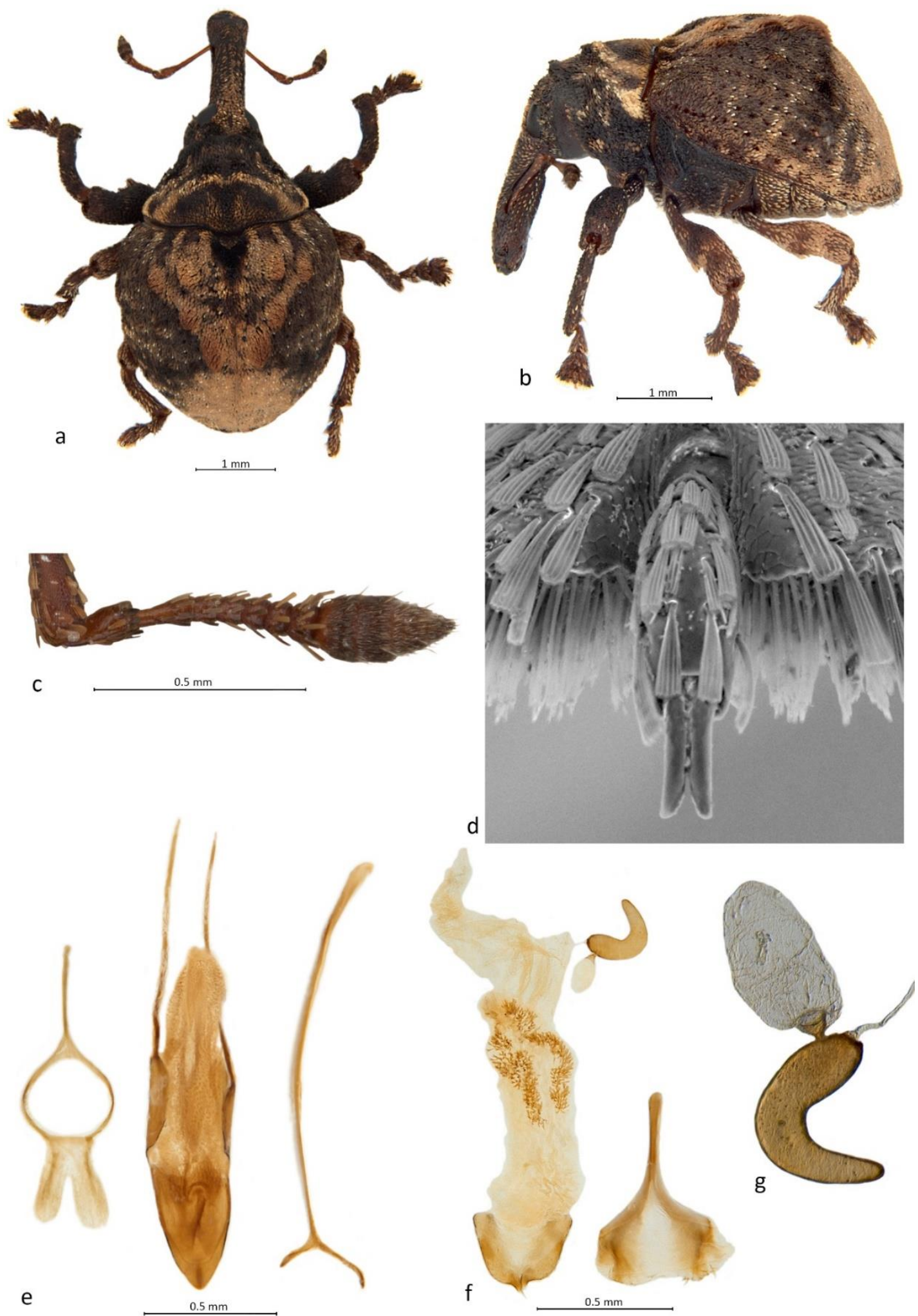

Figure 9. Habitus and diagnostic characters of Menechirus parryi sp. n.: (a) habitus of male, dorsal view; (b) habitus of male, left lateral view; (c) right antenna, male, dorsal view; (d) tarsite 3 with onychium, apical view; (e) genitalia, male, dorsal view; (f) genitalia, female, dorsal view; (g) spermatheca with gland. 


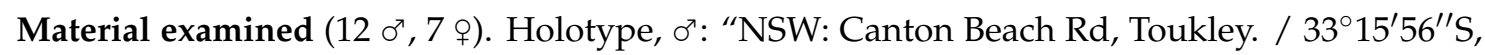
$151^{\circ} 32^{\prime} 26^{\prime \prime}$ E. / 08 May 2007. Cate Inwood. / Ex Syzygium paniculatum fruit. / 6 m street tree. Emerged: 22/06/2007 // $\sigma^{7} / /$ ANIC / Image // HOLOTYPE / Menechirus parryi / Jennings \& Oberprieler, 2018" (ANIC). Paratypes (all labelled "PARATYPE / Menechirus parryi / Jennings \& Oberprieler, 2018" in ANIC). 1 o: same data as holotype except "Emerged: 12/07/2007"; 1 '? “33 $16^{\prime} 17^{\prime \prime} \mathrm{S} 151^{\circ} 33^{\prime} 03^{\prime \prime} \mathrm{E} / \mathrm{NSW}$ : Noraville, Canton / Parade / 7 Mar 2008 P. Juniper / on Syzygium

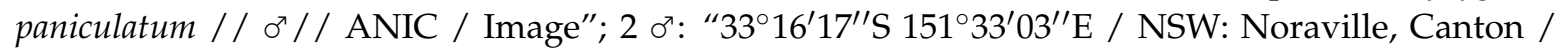
Parade / 7 Mar 2008 P. Juniper / on Syzygium paniculatum // o"; $10^{\text {": }: ~ " N S W: ~ W i n g h a m ~ / ~} 14$ Nov. 1990 ex / riparian r'for / G. Williams // on T.1. / Waterhousea / floribunda / blossom / / $\mathrm{o}^{71} ; 1 \mathrm{o}^{7}$ : "NSW: Wingham / 22 Nov. 1990 ex / riparian r'for / G. Williams T.I. / / on Waterhousia [sic] / floribunda / blossoms / / o // ANIC / Image"; $10^{7}:$ "2.3 km N Harrington / NSW 9 Oct. 1983 / G. Williams ex lit. / rainfor. Margin / / o"; 1 : “@3 km NE Harrington / NSW 13 Dec. 1985 / G. Williams ex /

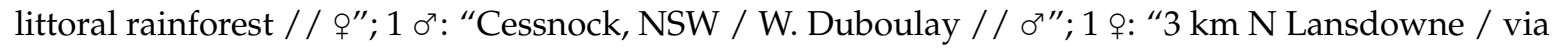
Taree NSW / 26 Sept. 1983 / G. Williams coll. / wet sclero. for. / /"; 1 q: “3 km, N. Lansdowne, / N.S.W. 29 Nov. 1991 / G. Williams. / ex Waterhousea / floribunda / blossoms / / q"; 1 : "Toowomba / 14 Dec 74 Q. / / / / ANIC / Image"; 1 q: "Peachester / 16 Dec. 68 / R.A. Yule / Dept. QLD / / ex

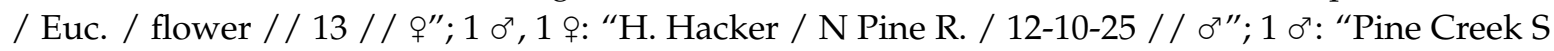
of / Bundaberg QLD / 23.xi.75 H. Frauca // o"”; 1 \%: "Pine Creek S of / Bundaberg QLD / 2.xii.75

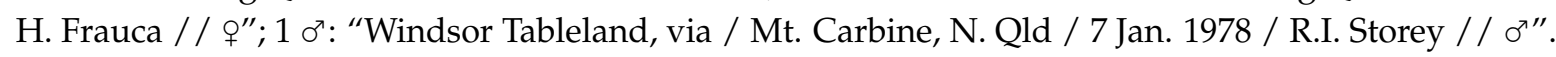

Distribution (Figure 13). Central coast of New South Wales to north-eastern Queensland (Cairns area).

Hostplants. Mainly Syzygium paniculatum, also S. australe and S. floribundum (Myrtaceae).

Derivation of name. This species is cordially named after David Parry, our local Leica representative, for his ongoing support and expert advice concerning our microscopes and the LAS imaging systems as well as for his unfailing humour, with which he brightens up our mundane taxonomic work.

Remarks. Menechirus parryi is most similar to M. mundus, differing externally in its more pronounced colour pattern of the elytra and internally in the shape of the penis, gonocoxites and spermatheca and, most distinctly, in the bursa possessing a pair of bands of spicules. It also appears to be separated from M. mundus geographically as it is not known to occur in the Northern Territory. From the other species occurring in Queensland, M. howdenae, M. parryi is easily distinguishable by its smaller size, different dorsal colour pattern and differences in the male and female genitalia. As in M. mundus, the males are distinguishable from the females by the patch of black scales behind the scutellar shield.

The larvae of this species can cause significant fruit loss on Syzygium paniculatum, an endangered tree species in New South Wales [30]. Juniper \& Britton [30] recorded the species from $51 \%$ of fruits sampled at five locations in central New South Wales, mostly based on adults emerging from pupal shelters among damaged fruits in rearing containers.

Menechirus mundus Jennings \& Oberprieler, sp. n. (Figure 10)

Description: Shape. Body short, ovoid, length 4.1-4.8 $\mathrm{mm}$ in both sexes (holotype $4.6 \mathrm{~mm}$ ), width ca. $0.7 \times$ length (Figure 10a), distinctly convex in lateral view (Figure 10b). Colour and vestiture. Body densely covered with pale brown to black scales (with few white scales scattered in between); head with pale scales on forehead and vertex, dark brown ones behind eyes; pronotum with brown scales except for 2 narrow, transverse bands of pale scales arching from sides of base across anterior half of disc and for more poorly defined areas of pale scales along base; elytra with pale scales except for a pair of large, dark lateral patches in middle, restricting pale scales into a narrow hour-glass shape, in male also with a median patch of black scales behind scutellar shield; venter and legs with mostly pale scales (Figure 10a). Rostrum. Short (as long as pronotum in male, 1.3 $\times$ longer in female), robust, straight, dorsoventrally slightly flattened, apically broadened in dorsal view, distal third 
coarsely punctate, proximal two-thirds indistinctly rugose with distinct median carina and indistinct dorsolateral carinae, no dorsomedian ones (Figure 10a,b). Eyes. Subcircular in outline, very slightly convex but not protruding (Figure 10b). Antennae. Inserted in apical third of rostrum; scapes not reaching to below anterior margin of eye in repose; funicles with segments 1 and 2 subequal, each almost $3 \times$ longer than each of segments 3 to 7 ; clubs shortly elongate, $2 \times$ longer than broad, finely pubescent (Figure 10c). Pronotum. Trapezoidal in shape, $2 \times$ wider at base than at apex; disc strongly convex, in centre with a pair of very slight, broadly separated elevations (not forming tubercles) with only a few or no black scales, a similar pair of elevations on anterior margin and another pair laterally, the posterior curved band of pale scales passing just behind central elevations and the anterior band just behind anterior and lateral elevations (Figure 10a,b). Scutellar shield. Broadly ovoid to roundly subtriangular, covered with broad pale scales. Elytra. $2.2 \times$ longer than pronotum, joint width subequal to length, wider than base of pronotum; humeri broadly rounded, hardly protruding; interstriae 1 in male slightly elevated at base, interstriae 2 with single elongate tubercle with a tuft of erect brown scales in middle of length, interstriae 3 with 2 more anteriorly placed, similarly tufted tubercles but anterior one very faint, interstriae 5 with similarly faint anterior tubercle only; single tubercle of interstriae 2, posterior tubercle of interstriae 3 and single tubercle of interstriae 5 demarcating posterior edge of anterior triangle of the pale hour-glass-shaped macula (Figure 10a). Legs. Femora with 2 unequal ventral teeth, anterior one minute; tibiae with premucro much smaller than uncus, especially on metatibiae; tarsi with claws parallel, very close together (Figure 10d). Genitalia. Penis elongate, very narrow $(7 \times$ longer than broad), sides subparallel, apically narrowly pointed, temones shorter than penis body, endophallus spinulose, without distinct internal sclerites (Figure 10e); bursa copulatrix without bands of spicules (Figure 10f), spermatheca weakly crescentic, thicker in basal than in apical half, gland large, narrowly rounded apically (Figure 10g).

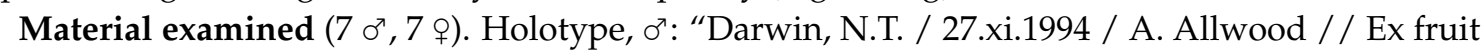
of / Eugenia sp. / / $\sigma^{7} / /$ ANIC / image / / HOLOTYPE / Menechirus mundus / Jennings \& Oberprieler, 2018" (ANIC). Paratypes (all labelled "PARATYPE / Menechirus mundus / Jennings \& Oberprieler, 2018" in ANIC) 60 " 6 \%: same data as holotype except "ANIC / image"; 1 \%: "Pickertaramoor /

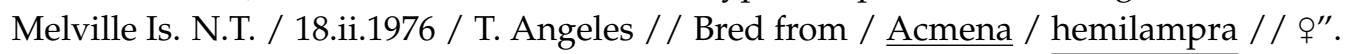

Distribution (Figure 13). North-western Northern Territory.

Hostplants. Syzygium hemilamprum (Myrtaceae) and possibly other species of Syzygium. The host recorded as Eugenia on labels is probably Syzygium hemilamprum too, which occurs in the Tiwi Islands and at least in the botanical garden in Darwin. It also occurs along the Queensland coast, but no specimens of M. mundus have been recorded from there.

Derivation of name. The name of the species is a Latin adjective meaning neat or elegant, in reference to its smoother pronotum and elytra compared with those of all other Menechirus species.

Remarks. Menechirus mundus is most similar to M. parryi, differing externally in its less pronounced colour pattern of the pronotum and elytra and internally in its genitalia, the penis being much narrower, the gonocoxites broader, the spermatheca of uneven thickness and, most distinctly, the bursa not possessing a pair of bands of spicules. However, all available specimens of M. mundus are teneral (reared from fruits), and the genitalia of mature specimens should be examined to verify these differences. Menechirus mundus also appears to be geographically separated from M. parryi, being only known from the north-western parts of the Northern Territory. 

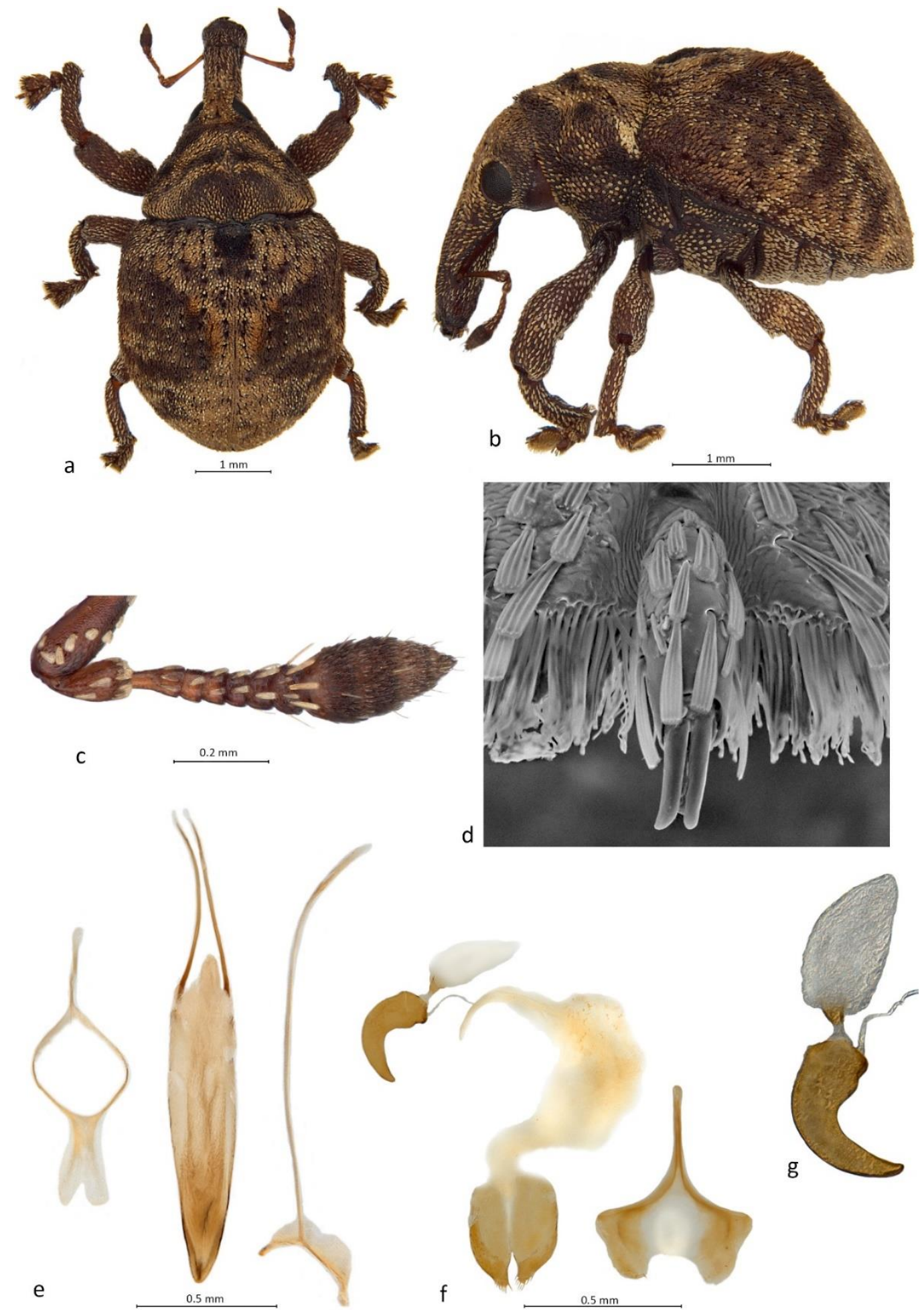

Figure 10. Habitus and diagnostic characters of Menechirus mundus sp. n.: (a) habitus of male, dorsal view; (b) habitus of male, left lateral view; (c) right antenna, male, dorsal view; (d) tarsite 3 with onychium, apical view; (e) genitalia, male, dorsal view; (f) genitalia, female, dorsal view; (g) spermatheca with gland. 


\subsection{Description of Kuschelorhynchus macadamiae gen. et sp. n.}

Genus Kuschelorhynchus Jennings \& Oberprieler, gen. n. (Figures 11 and 12)

Type species: Kuschelorhynchus macadamiae Jennings \& Oberprieler, sp. n.

Description: Shape. Body medium-sized, short and broad, robust, strongly sculptured. Colour and vestiture. Body densely covered with whitish, yellowish, reddish brown and dark brown, striate, imbricate scales, forming distinct colour pattern especially on pronotum and elytra. Rostrum. Short, robust, almost straight, subcylindrical at base but flattening and broadening apicad, dorsally strongly sculptured; laterally with deep, straight scrobes running onto venter of head, not quite meeting in middle but sharply bent into shallower grooves running parallel to each other anteriad almost to labium, receiving funicles and clubs when antennae retracted. Head. Spherical, densely squamose, dorsally impressed and tuberculate. Eyes. Subcircular in outline, slightly convex but not protruding. Antennae. Scapes almost straight, subcylindrical, gradually inflated distad, slightly longer than funicles, funicles 7 -segmented, with segment 1 about $2 \times$ longer than others, 7 appressed to club but distinct; clubs 3-segmented with small apical cone, shortly elongate, slightly compressed, finely pubescent. Thorax. Pronotum shortly trapezoidal, slightly constricted anteriorly, with pair of large, double-pointed central tubercles and smaller ones anteriorly and laterally; lateral margin not drawn into ocular lobes; procoxal cavities in about middle of prosternal length, separated by about one-third of their width. Scutellar shield elongate-ovoid, convex, densely squamose. Pterothoracic sclerites distinct; meso- and metacoxal cavities separated by nearly their width; mesoventrite very short, steeply sloping; metaventrite also short, transversely convex; metanepisternal sutures distinct, complete, without sclerolepidia. Elytra. As broad across humeri as long, with pair of large, flattened central tubercles and some smaller lateral ones in line towards humeri; at apex conjointly truncate, no pygidium exposed. Legs. Procoxae large, spherical; femora robust, subcylindrical, slightly sinuate, with large ventral tooth in middle of length and much smaller tooth immediately distally of it; tibiae straight, well compressed, at apex with strong uncus and smaller premucro in a tuft of long, testaceous setae; tarsi short, broad, compact, with onychium narrow, short, about as long as tarsite 1, claws small, slightly divergent. Abdomen. Ventrites 1 and 2 equal in length, almost $2 \times$ longer than 3 and 4, 5 slightly longer than 4 , apically broadly rounded. Genitalia. Penis elongate, with distinct tectal plate, temones shorter than penis body, endophallus with large, symmetrical, looped internal sclerite. Gonocoxites short, narrow, not well differentiated into proximal and distal parts, apically narrowed, bluntly rounded, with numerous long setae but no styli; bursa copulatrix bulbous, unsclerotised, ventrally at junction with vagina with a short, tubular extension braced by a stack of several semicircular, sclerotised bows, leading broadly into oviduct; spermatheca crescentic, not differentiated, cornu acute, gland bulbous with funnel-shaped, sclerotised stalk, spermathecal duct inserted dorsally on oviduct just anteriorly of sclerotised bows; sternite VIII short and broad, bladal part with large desclerotised median area, margin fringed with several stiff setae, apodeme shorter than bladal part, narrow.

Derivation of name. The genus is respectfully named for the late Guillermo (Willy) Kuschel (1918-2017), who contributed so much to the knowledge of the global and the Australian weevil faunas, including the Cryptoplini [13], and who has been a close friend and mentor of the second author for three decades. The genus name is masculine in gender; the second part of the name is latinised from the Greek noun rhynchos (snout), a common component of genus and species names in Curculionoidea.

Remarks. The genus is described for a single, striking Australian species of Cryptoplini that is associated with Macadamia (Proteaceae). Kuschelorhynchus is similar to Menechirus and Sigastus in having two small, separate tarsal claws, but it differs from these two genera in its pronotal and elytral sculpture and in its male and female genitalia, specifically in the endophallic sclerite of the male and the peculiar sclerotisation of the bursa/oviduct of the female, which are unique among Cryptoplini. It also differs from all other Cryptoplini in its host, the larvae developing in the fruits of Macadamia (Proteaceae) rather than in those of Myrtaceae. 
Kuschelorhynchus macadamiae Jennings \& Oberprieler, sp. n. (Figures 11 and 12)

Sigastus weevil: Fay et al. 2001: 137-140 [19]; Bright, 2017: 1-4 [21], 2017: 1-5 [22]

Sigastus new species 2: Juniper \& Britton, 2010: 300 [30]

Description: Shape. Body short, subhexagonal in outline, length 7.1-9.5 $\mathrm{mm}$ in both sexes (holotype $8.4 \mathrm{~mm}$ ), width ca. $0.75 \times$ length (Figure 11a), convex in lateral view with large tubercles on pronotum and elytra (Figure 11b). Colour and vestiture. Body densely covered with a mixture of silvery white, pale and dark brown scales, giving it a greenish-grey colour; head with complex pattern of dark brown and pale brown/whitish scales; pronotum greenish-grey except for centre and dorsal anterior margin around tubercles reddish-brown and reddish-brown elongate lateral patches (Figure 11c); elytra with pale greenish-grey scales on dorsum, darker greenish-grey ones laterally of tubercles up to interstriae 6 , interstriae 7,8 and 9 with dark reddish-brown scales laterally; legs banded with pale and dark brown scales interspersed with scattered white ones; venter largely with pale brown scales (Figure 11a). Rostrum. Short (about $0.8 \times$ as long as pronotum in both sexes), very robust, straight, dorsoventrally slightly flattened, apically broadened in dorsal view (Figure 11d,e), with sharp median carina throughout length and irregular dorsolateral ones, these interrupted and bridged above antennal insertions and ending in short, squamose tubercle between eyes (Figure 11d,e). Eyes. Subcircular in outline, slightly convex, not protruding (Figure 11d,e). Antennae. Inserted in apical third of rostrum; scapes reaching to below anterior margin of eye in repose (Figure 11e); funicles with segment $1 \mathrm{ca}$. $2 \times$ longer than 2, 3 to 7 progressively shorter towards club; clubs shortly elongate, $2.5 \times$ longer than broad in dorsal view (the narrow side), finely pubescent (Figure 11f). Pronotum. Trapezoidal in shape, $1.8 \times$ wider at base than at apex; disc strongly tumescent, culminating in a pair of tall, double-peaked central tubercles carrying a tuft of long, erect, reddish-brown setae, at anterior margin a similarly tufted inner pair of tubercles and a smaller outer pair, laterally of central pair another pair of smaller, squamose tubercles (Figure 11a-c). Scutellar shield. Elongate, strongly convex, densely covered with dark brown scales. Elytra. $2 \times$ longer than pronotum, joint width $0.95 \times$ length, $0.75 \times$ as broad as pronotum; humeri broadly rounded, slightly protruding; interstriae 1 slightly elevated behind scutellar shield and with black scales flanking it in both sexes, interstriae 2 without tubercles, interstriae 3 with small, squamose tubercle just behind scutellar shield and a huge elongate tubercle behind it, flattened on outer side and with yellowish scales on mesal and dark brown to black ones on outer side, interstriae 4 without tubercles but almost vertical on outside of large tubercle of interstriae 3, interstriae 5 with large, pointed anterior tubercle just anteriorly of tubercle of interstriae 3 and with smaller, flatter one on declivity involving also interstriae 4 and 6 next to and behind it, interstriae 6 with small anterior tubercle next to tubercle of interstriae 5 , all tubercles demarcating anterior and posterior sides of the large, brown, subtriangular lateral elytral macula (Figure 11a,b). Legs. Femora with two unequal ventral teeth, anterior one smaller (very small on metafemora); tibiae with premucro prominent but smaller than uncus (very small on metatibiae); tarsi with claws slightly divergent (Figure $11 \mathrm{~g})$. Genitalia. Penis shortly elongate $(5 \times$ longer than broad), sides parallel, apically rounded except for small apical point, temones $0.62 \times$ as long as penis body, endophallus with long, strongly sclerotised, looped internal sclerite, ventral part narrow, flat, dorsal part broad, apically cleft (Figure 12a,b); oviduct beneath bursa copulatrix with ca. 20 semicircular sclerotised bows stacked together (Figure 12c,d), spermatheca roundly crescentic, cornu acute, gland large, oval (Figure 12e). 

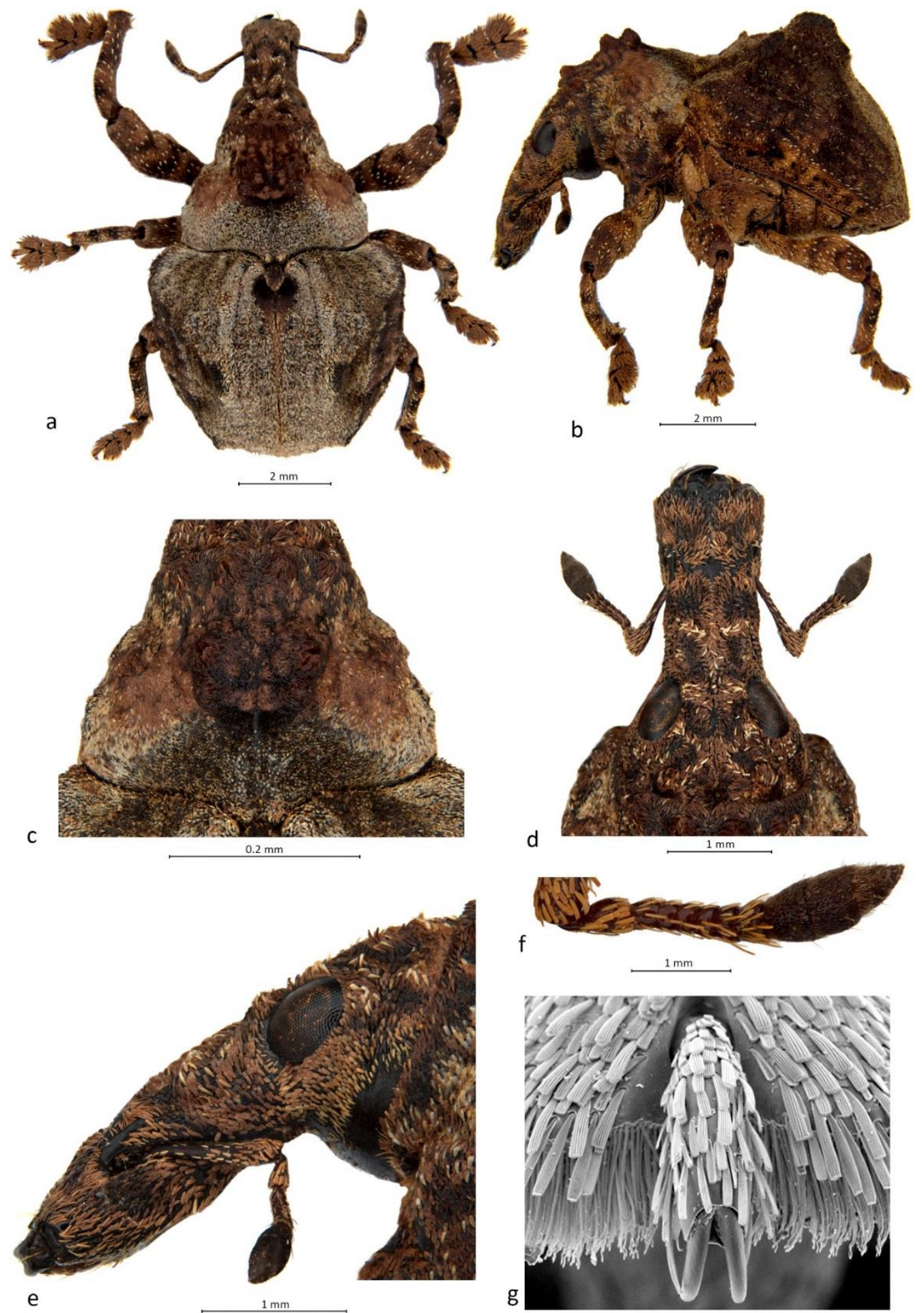

Figure 11. Habitus and diagnostic characters of Kuschelorhynchus macadamiae gen. \& sp. n.: (a) habitus of male, dorsal view; (b) habitus of male, left lateral view; (c) pronotum, dorsal view; (d) head and rostrum, dorsal; (e) head and rostrum, lateral; (f) right antenna, male, dorsal view; (g) tarsite 3 with onychium, apical view. 


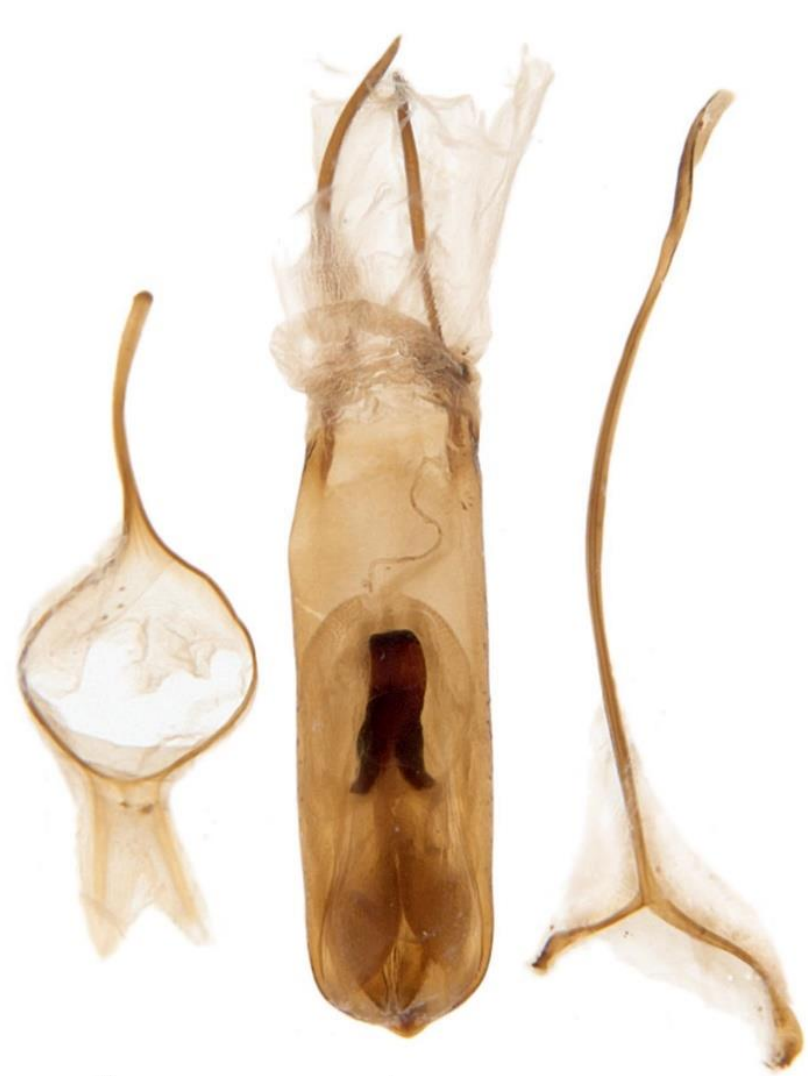

a

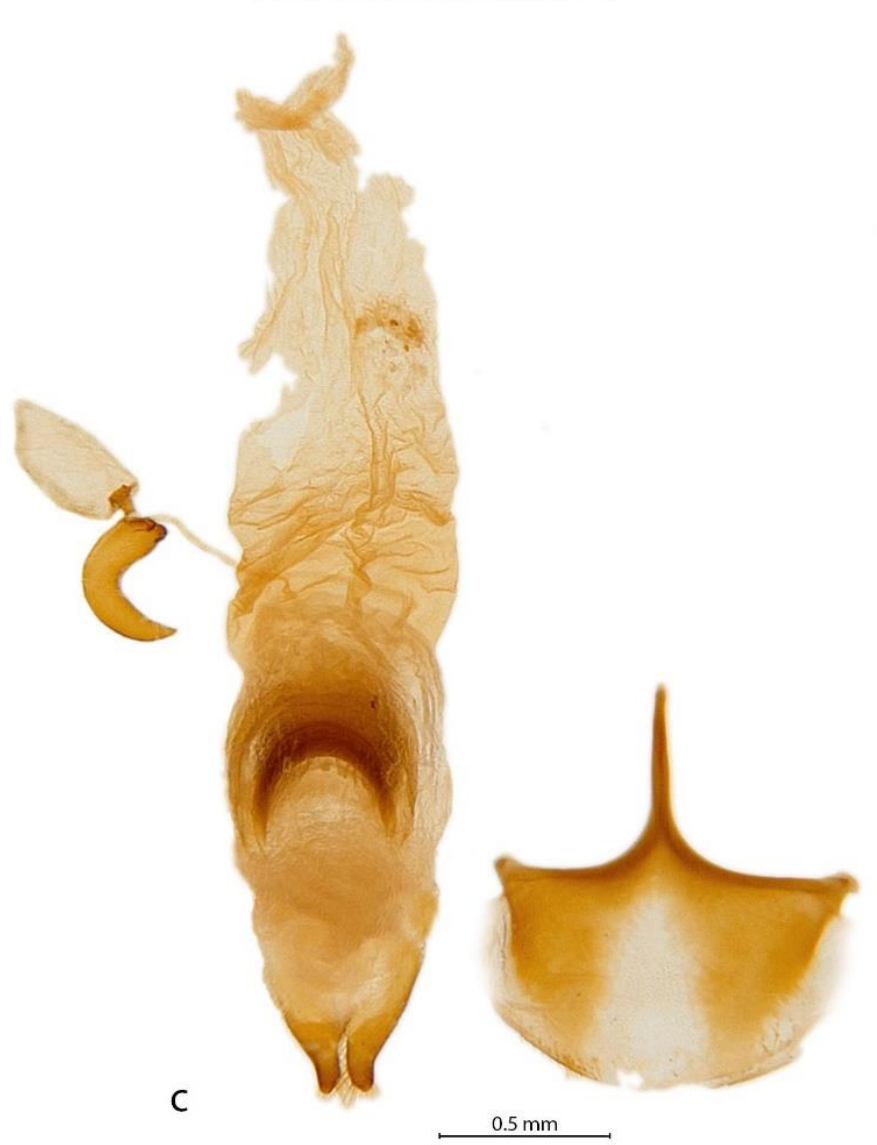

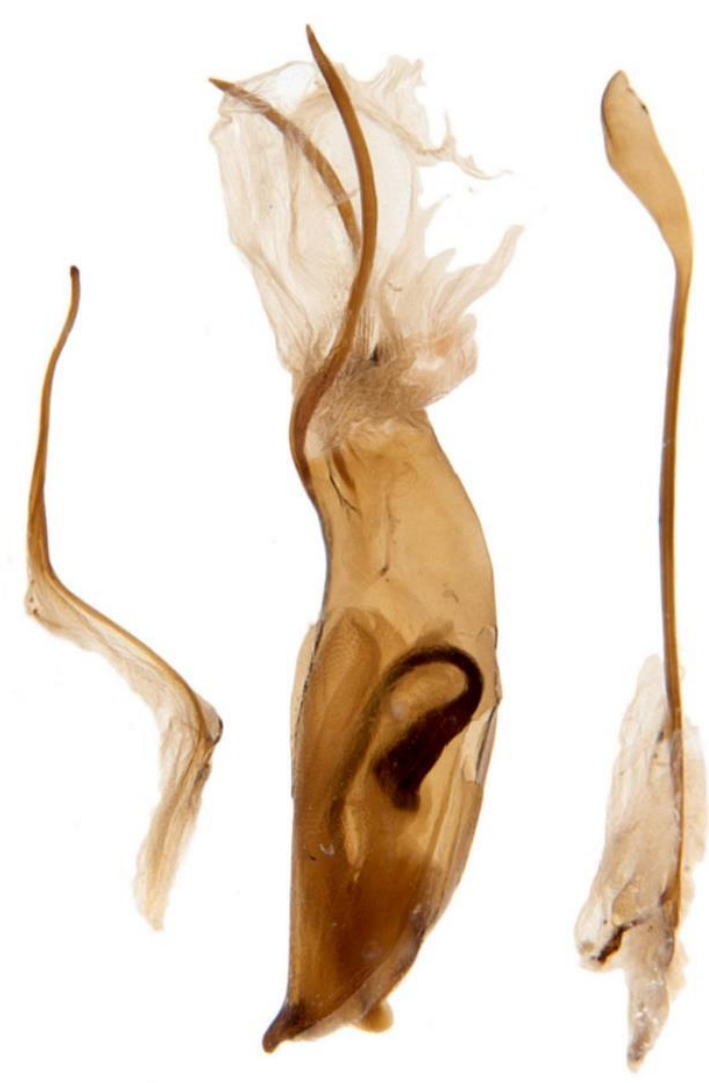

b

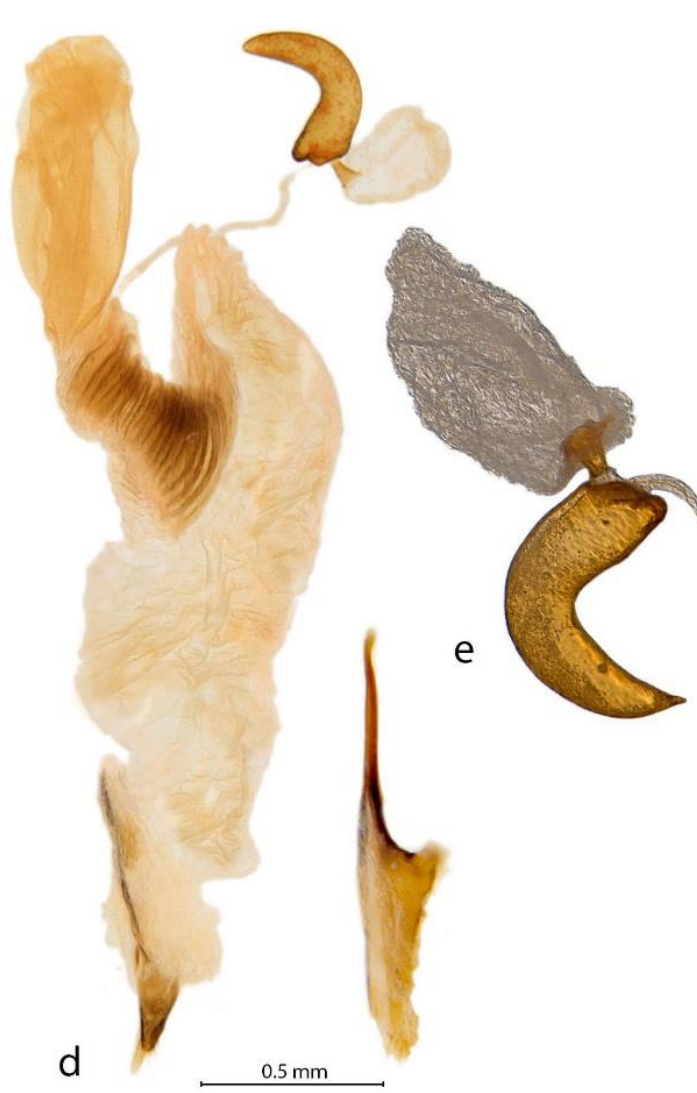

Figure 12. Genitalia of Kuschelorhynchus macadamiae gen. \& sp. n.: (a) genitalia, male, dorsal view; (b) genitalia, male, lateral view; (c) genitalia, female, dorsal view; (d) genitalia, female, lateral view; (e) spermatheca, female. 
Material examined (29 $\sigma^{7}, 38$ $)$ ). Holotype, $o^{7}$ : “Chewko Rd. Walkamin, Nth. Qld / Watkins Orchard / Ex-Macadamia / 28th. Nov 2001 / R. Blanche \& R. Bauer // ANIC / Image // $\sigma^{7} / /$ HOLOTYPE / Kuschelorhynchus macadamiae / Jennings \& Oberprieler, 2018" (ANIC). Paratypes (all labelled "PARATYPE / Kuschelorhynchus macadamiae / Jennings \& Oberprieler, 2018"): $\overline{10^{7}, 3 \text { q: same }}$ data as holotype (ANIC); 4 " , 1 q: "Walkamin, Nth. Qld / DPI Research Station / Ex-Macadamia / 7th. Nov 2001 / R. Blanche and R. Bauer" (ANIC, QMBA); 1 ;; "Atherton, Nth. Qld / Felderhofs Orchard / Ex-Macadamia / 27th. Nov 2001 / R. Blanche and R. Bauer / / o" (ANIC); 10 ", 4 o: "Wongabel Rd. Atherton, Nth. Qld / Robbins Orchard / Ex-Macadamia / 27th. Nov 2001 / R. Blanche and R. Bauer" (ANIC); 5 o: "Higgins Rd. Kairi, Nth. Qld / Rees Orchard / Ex-Macadamia / 27th. Nov 2001 / R. Blanche and R. Bauer / $\%$ " (ANIC, QMBA); $10^{\prime}, 2$ \%: “Tinaroo Rd. Kairi, Nth. Qld / Cummings Orchard / Ex-Macadamia / 27th. Nov 2001 / R. Blanche and R. Bauer" (ANIC); $10^{7}$ : "Emerald Ck. / Mareeba, Qld / 5.XI.1994 / J. Allen / / bred ex / Macadamia / fruit / / o"; 6 0", 11 o: "AUSTRALIA: n. Qld / Kay Rd, Emerald Ck / via Mareeba. 27.X.1994 / J. Allen and K. Lewis / Larvae feeding on / Macadamia fruit / / o" (ANIC, QDPI, QMBA); 2 o", 2 ㅇ: "Kay Rd. Mareeba, Nth. Qld / Reppels Orchard / Ex-Macadamia / 28th. Nov 2001 / R. Blanche and R. Bauer" (ANIC); 2 o': "Beantree Rd. Tolga, Nth. Qld / Staines Orchard / Ex-Macadamia / 26th Nov 2001/ R. Blanche and R. Bauer / / o" (ANIC); 19: “Beantree Rd. Tolga, Nth. Qld / Inderbitzens Orchard / Ex-Macadamia / 28th.Nov 2001 / R. Blanche and R. Bauer // क" (ANIC); 3 o': "Kennedy Hway. Tolga, Nth. Qld / O'Neils Orchard / Ex-Macadamia / 28th. Nov 2001 / R. Blanche and R. Bauer / / o" (ANIC); $70^{7}, 8$ ․:. "AUSTRALIA: n. Qld / Tolga 11-18.X.1994 / J. Watson / Larvae feeding on / Macadamia fruit / / $\sigma^{7 \prime \prime}$ (ANIC, CMNC, QDPI, QMBA); 1 o': “Tolga, Qld / 1.XI.1994 / J. Watson / live on Macadamia o" (ANIC); 10 ", 1 \%: "Tolga, Qld / 27.IX.1994 / J. Watson / / bred ex / seed / Macadamia" (QDPI).

Distribution (Figure 13). Recorded from north-eastern Queensland and north-eastern New South Wales but natural distribution outside of these areas of commercial macadamia plantations unknown, probably largely congruent with that of Macadamia along the east coast of Australia.

Host plants. Macadamia (Proteaceae). The commonly recorded host is likely to be the commercial hybrid cultivar M. tetraphylla / M. integrifolia. Whether K. macadamiae occurs on both these species also in the wild, and/or on the other two species in the genus Macadamia, M. jansenii, and M. ternifolia, and on closely related genera, is unknown.

Derivation of name. The species is named after its host genus, Macadamia, its name being a noun in the genitive case.

Remarks. The species has usually been referred to as the "Sigastus weevil" in publications dealing with macadamia pests [19-22], following its initial but tentative assignment to the genus Sigastus by Fay [19], although Blanche et al. [20] indicated that it was likely to belong to a different (undescribed) genus. This is confirmed by the present study and the description of both the species and the genus, and therefore its alternative common name, Macadamia Seed Weevil [22], is much more appropriate.

Kuschelorhynchus macadamiae emerged as a 'pest' of macadamia trees in plantations on the Atherton Tableland in 1994 [19] and continues to cause serious infestations of this crop there and in the region of the northern rivers in New South Wales [21,22], where it appeared more recently. Its life history and behaviour have been studied in some detail $[19,21,22]$. The female weevil scarifies the husk of green macadamia fruits ('nuts') with her mandibles and then lays a single egg into the husk. She then severs the stalk of the fruit so that it drops to the ground. The larva feeds on the kernel and pupates in the fruit, from which the next-generation adult emerges about two months later. Infestation rates (crop loss) in plantations average about $30 \%$ but can be as high as $73 \%$. Control is achieved by a combination of insecticide application (to kill the adults) and orchard sanitation (removing the dropped fruits with developing larvae). Exposure of the infested fruits to sunlight was also found to cause $100 \%$ mortality of the larvae [19]. Being a native insect with presumably natural hosts in areas surrounding macadamia plantations, Kuschelorhynchus macadamiae stands to re-infest plantations every season. 


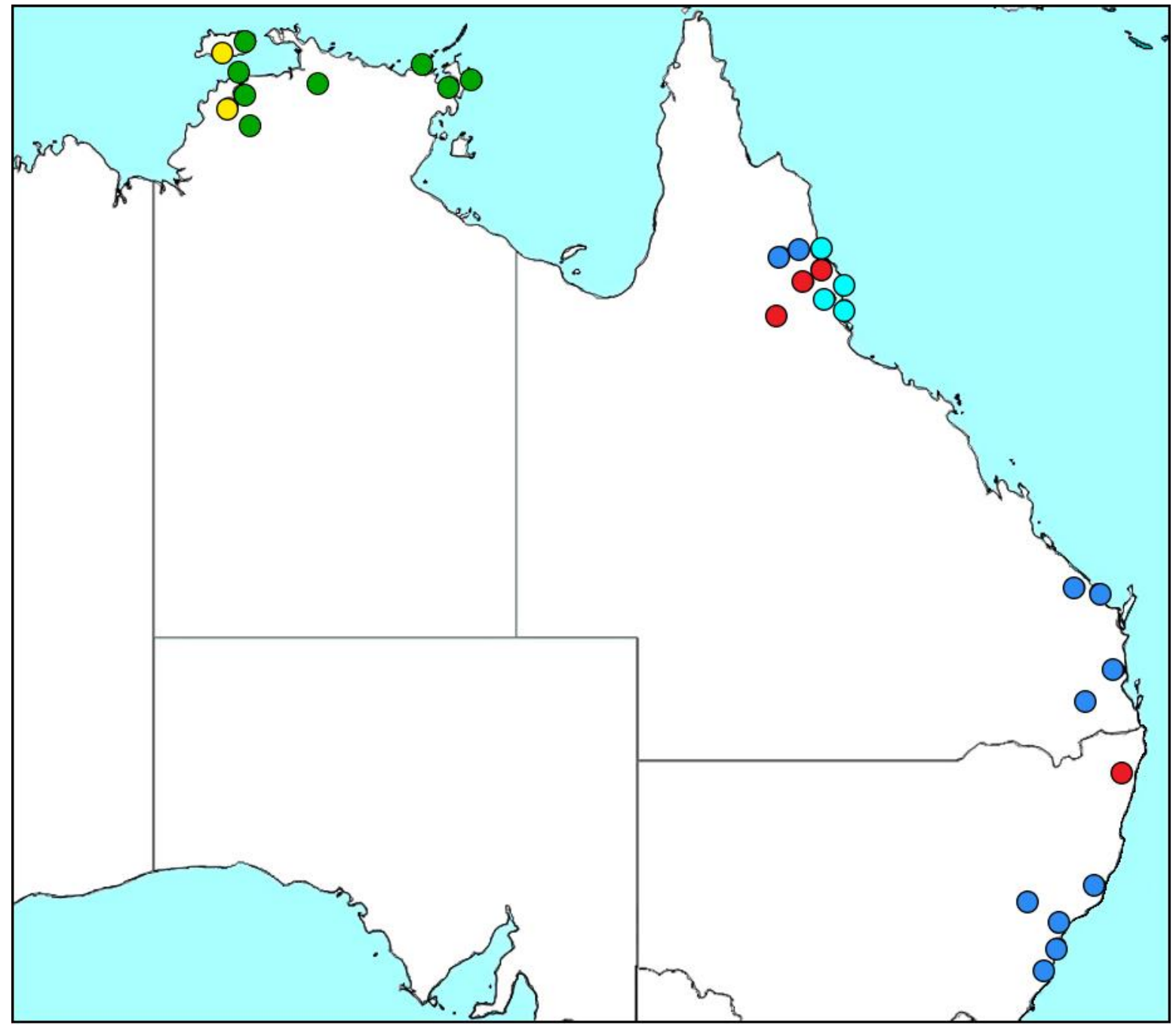

Menechirus fuscodorsalis

Menechirus howdenae

Menechirus parryi

Menechirus mundus

Kuschelorhynchus macadamiae

Figure 13. Distribution of the species of Menechirus Hartmann and Kuschelorhynchus gen. n. in Australia.

\section{Discussion}

The most intriguing feature of the Cryptoplini is the apparent pedotectal structure of their penis. This type of penis, consisting of distinct ventral and dorsal parts, respectively the pedon and tectum, is characteristic of the more basal families of weevils (Nemonychidae to Brentidae) as well as of the basal lineages of Curculionidae (Brachycerinae-Erirhininae), whereas the 'higher' Curculionidae (the CEGH and CCCMS clades [35]) have a pedal type of penis, without a tectum. There are other differences between these two types of male genitalia in weevils too, concerning the structure of the temones and the tegmen as well as of the sternites VIII and IX associated with the aedeagus. In the typical pedotectal aedeagus, the temones have two basal arms (a dorsal one connecting to the tectum and a ventral one to the pedon), the tegmen has a large dorsal plate with short parameral lobes and is laterally articulated, sternite VIII is complete and typically carries a small spiculum relictum [36], and sternite IX has a large basal plate, whereas in the pedal aedeagus the temones only have a ventral arm (connected to the pedon), the tegmen has a dorsal pair of narrow parameres and is laterally not hinged, sternite VIII is divided into two crescentic hemisternites, and in sternite IX the basal plate forms a narrow fork [37]. 
As the pedotectal type occurs in the phylogenetically more basal weevil families as well as in those of the sister-group of Curculionoidea, the Chrysomeloidea, it is regarded as the plesiomorphic type, with the pedal type indicated to be more derived and a possible apomorphy of the 'higher' curculionids. The transition between these two types is not entirely clear as few cases of obvious intermediary forms appear known, although it is evident that the tectum may become reduced from the sides, becoming thread-like (as in Perieges Schoenherr of Cryptolaryngini [36]), or become shorter and desclerotised (as in many species of Echinocnemus Schoenherr of Erirhinini), before vanishing completely. An apparent further step in this reduction of the tectum is represented by the genus Cranoides Kuschel (Cranopoeini), in which the remnants of the dorsal temonal arms remain, but unconnected to a tectum [13]. A similar condition also occurs in several species of Echinocnemus. In the pedal penis, the dorsal side of the pedon is usually membranous (the penis dorsally 'open'), but the lateral walls may extend dorsad and meet along the midline for a shorter or longer distance, sometimes transforming the pedon into a closed tube.

In Cryptoplini a different type of reduction of the pedotectal penis may have taken place. In all of the species examined, the penis has a distinct, long dorsal plate that is fused to the pedon at the base but free and tongue-like at the apex (Figure 14). It is slightly narrower and shorter than the pedon and laterally membranously connected to it along the basal two-thirds of its length, but in the apical third it is laterally free and flexible up and down, allowing the internal sclerite of the endophallus to evert through the ostium (beneath the tip of the dorsal plate) during copulation. Apart from the basal fusion, this plate is very similar to the tectum of the pedotectal penis. In the other genital structures, the aedeagus of the Cryptoplini is not of the pedotectal type, in that the temones have no dorsal (tectal) arm, the ring of the tegmen is laterally fused, its dorsal part consists of long parameres (though medially fused along most of their length), the basal plate of sternite IX is narrowly forked and sternite VIII is divided into two hemisternites. Two interpretations of this tectal plate in Cryptoplini appear plausible: either it is the remnant of the tectum of more primitive weevils, resulting not from a sideways reduction of the tectum but from a basal fusion of tectum and pedon (i.e., it is homologous with the tectum), or it is a secondary, sclerotised, tectum-like elongation and extension the dorsal membrane of the pedon formed after the complete reduction of the tectum (i.e., it is analogous with the tectum). A more detailed examination of this unique plate is required to understand its origin, but either way it is a seemingly unique feature of the tribe Cryptoplini. 

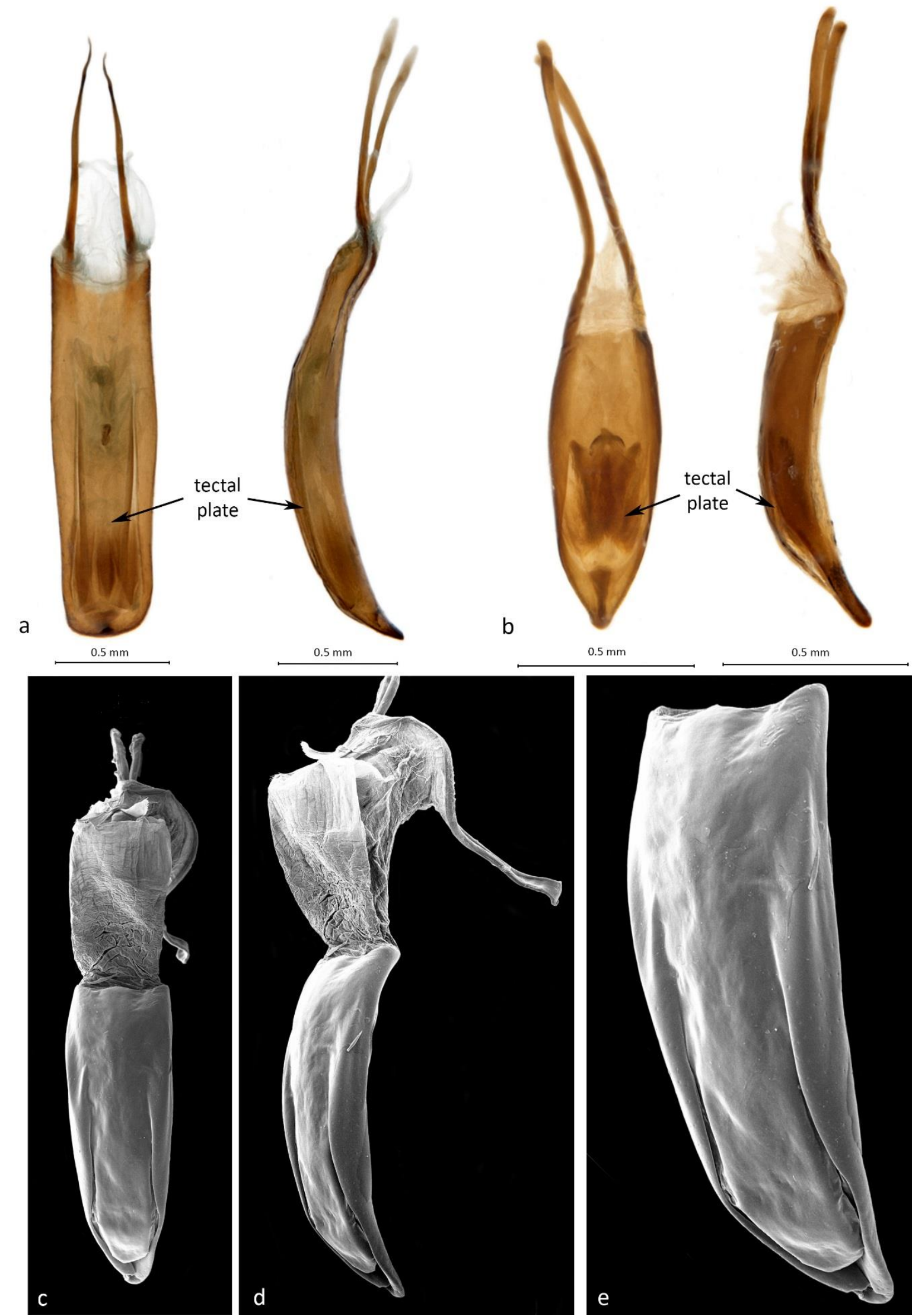

Figure 14. Tectal plates of Cryptoplini: (a) penis of Sigastus fascicularis Pascoe, dorsal and lateral view; (b) penis of Haplonyx casuarinae (Lea), dorsal and lateral view; (c) aedagus of Haplonyx maximus Lea, dorsal view (tegmen pulled forward over temones); (d) aedagus of Haplonyx maximus Lea, dorsolateral view (tegmen pulled forward over temones); (e) apical part of penis of Haplonyx maximus Lea, dorsolateral view. 
Author Contributions: Both authors contributed equally to the design, analysis and writing of the paper.

Funding: This research received no specific external funding.

Acknowledgments: We thank Robert Anderson (CMNC) for contributing the data of the Kuschelorhynchus specimens in his museum and two referees for their helpful comments on the manuscript.

Conflicts of Interest: The authors declare no conflict of interest.

\section{References}

1. Caldara, R.; Franz, N.M.; Oberprieler, R.G. 3.7.10 Curculioninae Latreille, 1802. In Handbook of Zoology. Coleoptera, Beetles (Phytophaga: Chrysomeloidea, Curculionoidea): Morphology and Systematics; Leschen, R.A.B., Beutel, R.G., Eds.; Walter de Gruyter GmbH: Berlin, Germany; Boston, MA, USA, 2014; Volume 3, pp. 589-628, ISBN 978-3-11-027370-0.

2. Lacordaire, T. Histoire Naturelle des Insectes. In Genera des Coléoptères ou Exposé Méthodique et Critique de tous les Genres Proposés Jusqu'ici dans cet Ordre d'Insectes; Tome Sixième; Librairie encyclopédique de Roret: Paris, France, 1863; 637p. [CrossRef]

3. Erichson, W.F. Beitrag zur Insecten-Fauna von Vandiemensland, mit besonderer Berücksichtigung der geographischen Verbreitung der Insecten. Arch. Naturgesch. 1842, 8, 83-287. [CrossRef]

4. Lea, A.M. Notes on some miscellaneous Coleoptera, with descriptions of new species. Part VIII. Trans. R. Soc. S. Aust. 1931, 55, 39-64.

5. Pascoe, F.P. Contributions towards a knowledge of the Curculionidae [part]. J. Linn. Soc. Lond. Zool. 1870, 10, 434-458. [CrossRef]

6. Alonso-Zarazaga, M.A.; Lyal, C.H.C. A World Catalogue of Families and Genera of Curculionoidea (Insecta: Coleoptera) (excepting Scolytidae and Platypodidae); Entomopraxis: Barcelona, Spain, 1999; 315p, ISBN 84-605-9994-9.

7. Lea, A.M. The clawless and apparently clawless Curculionidae of Australia. Trans. R. Soc. S. Aust. 1927, 51, 144-168.

8. Lea, A.M. Descriptions of new species of Australian Coleoptera. Part IV. Proc. Linn. Soc. N. S. W. 1897, 22, 584-638. [CrossRef]

9. Lea, A.M. Descriptions of Australian Curculionidae, with notes on previously described species. Part VIII. Trans. R. Soc. S. Aust. 1910, 34, 13-58.

10. Lea, A.M. Notes on Australian Curculionidae in the collection of the German Entomological National Museum of Berlin (Col.). Deutsch. Entomol. Z. 1910, 153-172, 505-526.

11. Lea, A.M. Australian Curculionidae of the subfamilies Haplonycides and Cryptorhynchides. Trans. R. Soc. S. Aust. 1928, 52, 95-164.

12. Zimmerman, E.C. Australian Weevils (Coleoptera: Curculionoidea). Volume I. Orthoceri. Anthribidae to Attelabidae. The Primitive Weevils; CSIRO: Melbourne, Australia, 1994; p. xxxii + 741, ISBN 0643105603, 9780643105607.

13. Kuschel, G. New tribe, new genus and species for an Australasian weevil group with notes and keys [Coleoptera, Curculionidae]. Revue Française d'Entomologie (Nouvelle Series) 2009, 30, 41-66.

14. Schenkling, S.; Marshall, G.A.K. Haplonychinae. In Curculionidae: Prionomerinae, Aterpinae, Amalactinae, Haplonychinae, Omophorinae; Coleopterorum Catalogus Auspiciis et Auxilio W. Junk; Pars 150; Schenkling, S., Ed.; W. Junk: 's-Gravenhage, The Hague, The Netherlands, 1936; pp. 1-8.

15. Pullen, K.R.; Jennings, D.; Oberprieler, R.G. Annotated catalogue of Australian weevils (Coleoptera: Curculionoidea). Zootaxa Monogr. 2014, 3896, 1-481. [CrossRef] [PubMed]

16. Froggatt, W.W. Australian Insects; W. Brooks \& Co.: Sydney, Australia, 1907; 449p, ISBN 4444006657824.

17. Morgan, W.L. Flies and nematodes associated in flower bud galls of spotted gum. Agric. Gaz. N. S. W. 1933, $44,125-127$.

18. Newman, L.J.; Clark, J. The tuart bud weevil (Haplonyx tibialis). J. Dep. Agric. West Aust. 1924, 1, 351-360.

19. Fay, H.A.C.; De Faveri, S.G.; Storey, R.I.; Watson, J. Sigastus weevil-An emerging pest of macadamias in north Queensland. In Proceedings of the Sixth Workshop for Tropical Agricultural Entomologists, Darwin, Australia, 10-15 May 1998; Young, G., Ed.; Technical Bulletin. Department of Primary Industry and Fisheries: Darwin, Australia, 2001; Volume 288, pp. 137-140. 
20. Blanche, R.; Bauer, R.; Cunningham, S.; Floyd, R. Services and Dis-Services of Rainforest Insects to Crops in North Queensland; Cooperative Research Centre for Tropical Rainforest Ecology and Management: Cairns, Australia, 2002; pp. 1-20.

21. Bright, J. Sigastus Weevil Update; Australian Macadamia Society: Lismore, Australia, 2017; pp. 1-4.

22. Bright, J. Sigastus weevil, life-cycle and monitoring. Primefact 2017, 1586, 1-5.

23. Oberprieler, R.G.; Anderson, R.S.; Marvaldi, A.E. 3 Curculionoidea Latreille, 1820: Introduction, Phylogeny. In Handbook of Zoology. Arthropoda: Insecta. Coleoptera, Beetles. Volume 3: Morphology and Systematics (Phytophaga); Leschen, R.A.B., Beutel, R.G., Eds.; Walter de Gruyter: Berlin, Germany; Boston, MA, USA, 2014; pp. 285-300.

24. Lacordaire, T. Histoire Naturelle des Insectes. Genera des Coléoptères ou Exposé Méthodique et Critique de tous les Genres Proposés Jusqu'ici dans cet Ordre D'insectes. Tome Septième; Librairie Encyclopédique de Roret: Paris, France, $1865 ; 620 \mathrm{p}$.

25. May, B.M. An introduction to the immature stages of Australian Curculionoidea. In Australian Weevils (Coleoptera: Curculionoidea). Volume II. Brentidae, Eurhynchidae, Apionidae and a Chapter on Immature Stages by Brenda May; Zimmerman, E.C., Ed.; CSIRO: Melbourne, Australia, 1994; pp. 365-721, ISBN 9780643051461.

26. Howden, A.T. Structures related to oviposition in Curculionoidea. Mem. Entomol. Soc. Wash. 1995, 14, 53-100.

27. Schoenherr, C.J. Genera et Species Curculionidum, cum Synonymia Hujus Familiae. Species Novae aut Hactenus Minus Cognitae, Descriptionibus a Dom. In Boheman et Entomologis Aliis, Illustratae; Tomus Tertius, Pars Secunda; Leonardo Gyllenhal, C.H., Ed.; Roret: Paris, France; Fred. Fleischer: Leipzig, Germany, 1836; 356p.

28. Pascoe, F.P. On some new genera of Curculionidae. Part 1. J. Entomol. 1865, 2, 413-432.

29. Fuller, C. Notes and descriptions of some species of Western Australian Coccidae. Trans. Entomol. Soc. Lond. 1899, 435-473. [CrossRef]

30. Juniper, P.A.; Britton, D.R. Insects associated with the fruit of Syzygium paniculatum (Magenta Lillypilly) and Syzygium australe (Brush Cherry). Aust. J. Entomol. 2010, 49, 296-303. [CrossRef]

31. Pascoe, F.P. Contributions towards a knowledge of the Curculionidae. Part III. J. Linn. Soc. Lond. Zool. 1872, 11, 440-492. [CrossRef]

32. Hartmann, F. Neue Rüsselkäfer aus Kaiser-Wilhelms-Land. Deutsche Entomol. Z. 1901, 2, 273-295. [CrossRef]

33. Klima, A. Subfam. Trigonocolinae. In Curculionidae: Alophinae, Diabathrariinae, Rhynchaeninae, Ceratopinae, Trigonocolinae, Xiphaspidinae, Nerthopinae, Euderinae, Camarotinae, Acicnemidinae; Coleopterorum Catalogus Auspiciis et Auxilio W. Junk; Pars 145; Schenkling, S., Ed.; W. Junk: 's-Gravenhage, The Hague, The Netherlands, 1935; 76p, (In 10 Separately Paginated Parts).

34. Heller, K.M. New Philippine Coleoptera. Philipp. J. Sci. 1922, 19, 523-627. [CrossRef]

35. Gunter, N.L.; Oberprieler, R.G.; Cameron, S.L. Molecular phylogenetics of Australian weevils (Coleoptera: Curculionoidea): Exploring relationships in a hyperdiverse lineage through comparison of independent analyses. Aust. Entomol. 2016, 55, 217-233. [CrossRef]

36. Thompson, R.L. Observations on the morphology and classification of weevils (Coleoptera, Curculionoidea) with a key to major groups. J. Nat. Hist. 1992, 26, 835-891. [CrossRef]

37. Oberprieler, R.G. 3.7.1 Brachycerinae Billberg, 1820. In Handbook of Zoology. Arthropoda: Insecta. Coleoptera, Beetles. Volume 3: Morphology and Systematics (Phytophaga); Leschen, R.A.B., Beutel, R.G., Eds.; Walter de Gruyter: Berlin, Germany; Boston, MA, USA, 2014; pp. 424-451.

(C) 2018 by the authors. Licensee MDPI, Basel, Switzerland. This article is an open access article distributed under the terms and conditions of the Creative Commons Attribution (CC BY) license (http://creativecommons.org/licenses/by/4.0/). 